\title{
Core/Shell Template-Derived Co, N-Doped Carbon Bifunctional Electrocatalysts for Rechargeable Zn-Air Battery
}

\author{
Yanlong Lv, ${ }^{1}$ Lin Zhu, ${ }^{1}$ Haoxiang Xu, ${ }^{1}$ Liu Yang, ${ }^{1}$ Zhiping Liu, ${ }^{1 *}$ Daojian Cheng, ${ }^{1}$ Xiaohua Cao, ${ }^{2}$ Jimmy Yun ${ }^{3}$ and Dapeng Cao ${ }^{1,2^{*}}$
}

Rationally design the nonprecious metal electrocatalysts to replace precious Pt-based catalysts is significantly important to boost the development of low cost fuel cells and metal-air batteries. Here, we propose a core/shell template strategy to synthesize nonprecious metal and nitrogen-doped porous carbons as efficient oxygen bifunctional electrocatalysts for Zn-air batteries. As a typical sample of the strategy, we use a ZnO@ZIF-67 core/shell nanoparticle (NP) as a self-sacrificed template and mix with additional nitrogen/carbon sources to synthesize Co/N-doped porous carbon catalysts. The resulting catalysts not only show almost similar activity with commercial $20 \mathrm{wt} \% \mathrm{Pt} / \mathrm{C}$ for oxygen reduction reaction (ORR), but also exhibit comparable activity with $\mathrm{IrO}_{2}$ for oxygen evolution reaction (OER) in alkaline medium. We further use density functional theory to investigate ORR/OER mechanism of $\mathrm{Co} / \mathrm{N}$-doped carbon catalysts, and reveal that the highly efficient electrocatalysts can be designed rationally by using $\mathrm{N}$-doped carbons to encapsulate electrophilic components, like metallic Co clusters. As a result, the catalyst-based $\mathrm{Zn}$-air battery also shows a higher power density of $\sim 185 \mathrm{~mW} \mathrm{~cm}^{-2}$ and a superior durability $(30 \mathrm{~h})$ than the Pt-IrO ${ }_{2}$ catalyst-based counterpart. This work provides an efficient core/shell template strategy for development of bifunctional catalysts for rechargeable $\mathrm{Zn}$-air battery.

Keywords: Core/shell template; Co/N-doped porous carbons; Metal-organic frameworks; Oxygen reduction reaction; Oxygen evolution reaction; Density Functional Theory

Received 15 January 2019, Accepted 28 February 2019

DOI: $10.30919 / \mathrm{es} 8 \mathrm{~d} 768$

\section{Introduction}

Growing demands of global energy greatly stimulate the development of sustainable energy conversion and storage systems, such as fuel cells, water electrolysis, lithium sulfur batteries and metal-air batteries, owing to their high efficiency, low cost and friendly environment. ${ }^{1-6}$ Among the renewable-energy technologies, Zn-air batteries have several advantages like high theoretical energy density (1086 $\left.\mathrm{Wh} \mathrm{kg}^{-1}\right)$, and low cost. $^{7,8}$ However, the slow rates of the oxygen reduction reaction (ORR) and oxygen evolution reaction (OER) ${ }^{9-13}$ severely limit the efficiency of Zn-air batteries. ${ }^{14-16}$ Currently, Pt and its alloys still are the most efficient catalysts for ORR while $\mathrm{Ru}$ and $\mathrm{Ir}$ oxides are the most efficient catalysts for OER. Although these noble metals possess excellent electrocatalytic performance, they suffer from several drawbacks like scarcity, high cost and poor long-time durability. ${ }^{17}$ Therefore, developing a high efficient nonprecious metal bifunctional oxygen electrocatalyst is very significant to solve the bottleneck of Zn-air batteries depending on noble metals, because a bifunctional oxygen catalyst can perform the discharging and charging of a $\mathrm{Zn}$-air battery simultaneously, which would reduce the cost significantly.

Currently, there are several strategies to reduce the amount of

State Key Laboratory of Organic-Inorganic Composites and Beijing Advanced Innovation Center for Soft Matter Science and Engineering, Beijing University of Chemical Technology, Beijing 100029, China

College of Chemical and Environmental Engineering, Jiujiang University, Jiujiang, Jiangxi 332005, China

School of Chemical Science and Engineering, The University of New South Wales, Sydney, NSW 2052, Australia

*E-mail: liuzhp@mail.buct.edu.cn; caodp@mail.buct.edu.cn noble metal in ORR and OER and other energy devices, such as Ptbased catalysts, nonprecious metal catalysts (NPMCs) and metal-free catalysts. $^{18-25}$ Although tremendous progress has been made in the individual ORR and OER catalysts, developing highly efficient bifunctional catalysts for both ORR and OER is still a great challenge. ${ }^{26-}$

${ }^{33}$ Generally, the pyrolysis plays a vital role in the preparation of most porous carbon electrocatalysts with high ORR/OER activity. However, the pyrolysis process at high temperature often leads to the collapse of the precursor structure and cause the loss in porosity and graphitization. Sufficient porosity of the electrocatalysts is favored in a typical process of ORR or OER, as it will enhance the mass transport and further accelerate the catalytic reaction. Recently, the self-sacrificing templates have been applied to guide the formation of nanopores. ${ }^{3440}$ Using metalorganic frameworks (MOFs) / covalent organic frameworks (COFs) as self-sacrificing templates to prepare the electrocatalysts has attracted wide attention, because MOFs/COFs not only hold their inherent porous structures and abundant carbon and nitrogen species, but also allow for control of the relatively exact locations of heteroatoms in the doped nanostructure. $^{41-48}$ Xiang and coworkers adopted 2D COPs as a selfsacrificing template to produce nitrogen-doped holey graphene-like electrocatalysts with relatively exact location of nitrogen, which shows good activity as a metal-free electrocatalyst. ${ }^{49}$ Guo and coworkers characterized the ORR active site by using newly designed graphite model catalysts with well-defined $\pi$ conjugation and well-controlled doping of $\mathrm{N}$ species, and revealed that the pyridinic nitrogen is beneficial for enhancing ORR activity ${ }^{50}$. Lou et al. used ZIF-67 as selfsacrificing template to synthesize the porous carbon electrocatalysts with the good location of $\mathrm{Co}$ and $\mathrm{N}$ atoms, and the resulting catalysts show better ORR activity than commercial $20 \mathrm{wt} \% \mathrm{Pt} / \mathrm{C}$ and comparable OER activity with $\mathrm{IrO}_{2}$ in alkaline media. ${ }^{51}$ Further, they adopted a facile 
anion-exchange method to synthesis ZIF-67/Co-Fe Prussian blue analogue (PBA) yolk-shell nanocubes as precursors. After annealing, the as derived $\mathrm{Co}_{3} \mathrm{O}_{4} / \mathrm{Co}$-Fe oxide double-shelled nanoboxes show enhanced OER activity in alkaline media. ${ }^{52}$

However, the direct pyrolysis of MOFs often leads to the aggregation of metal atoms. The aggregated metal atoms would turn into non-active sites for ORR/OER and needs to be removed by additional process, such as acid leaching. Recently, our group showed the first example of using ZIF-derived porous carbons as metal-free electrocatalysts and obtained the comparable catalytic activity with commercial $20 \mathrm{wt} \% \mathrm{Pt} / \mathrm{C}^{53}$ in which $\mathrm{Zn}$ atoms in $\mathrm{ZIF}$ template was served as activity agents to activate the resulting samples, because at high temperature $\mathrm{T}=950{ }^{\circ} \mathrm{C}$, the evaporation etching of the $\mathrm{Zn}$ would cause the formation of micropores and mesopores of samples. Then, the $\mathrm{Zn}$ evaporation etching method was also applied to the ZIF-8 derived porous carbons $^{54,55}$ and ZIF-8@ZIF-67 derived porous carbon catalysts. ${ }^{56}$

To achieve the replacement of noble metals (say, Pt and $\mathrm{RuO}_{2}$ ) with non-precious metals, here, we propose a core/shell template synthesis strategy in which the special core/shell NPs are used as a selfsacrificed precursor to prepare the non-precious metal/ $\mathrm{N}$-doped porous carbons as bifunctional electrocatalysts for ORR and OER. In this strategy, the core of NPs is low boiling agent (say, Zn), which will be vaporized in a pyrolysis process, while the shell of NPs is composed of desired non-precious metals (say, $\mathrm{Co}, \mathrm{Fe}, \mathrm{Ni}, \mathrm{Mn}$ ) and heteroatoms. During the pyrolysis, when the temperature is higher than the boiling point of the agents in the core, the agents will be vaporized and therefore activate the resulting samples spontaneously. The detailed synthesis route is illustrated in Fig. 1, where the core/shell ZnO/ZIF-67 NPs are considered as a representative example. By carbonizing the $\mathrm{ZnO} / \mathrm{ZIF}-67 \mathrm{NPs}$ and additional N/C source, we synthesize $\mathrm{Co} / \mathrm{N}$ doped porous carbon bifunctional catalysts. The as-synthesized samples not only show almost similar ORR activity with commercial $20 \mathrm{wt} \%$ $\mathrm{Pt} / \mathrm{C}$, but also exhibit comparable OER activity with $\mathrm{IrO}_{2}$ in alkaline medium. In order to understand the origin of excellent performance of $\mathrm{Co} / \mathrm{N}$-doped porous carbon as a bifunctional catalyst for ORR and OER, we also use density functional theory (DFT) to further reveal
ORR/OER mechanism of the Co/N-doped porous carbon catalysts. Due to the excellent ORR and OER activities, we assembled rechargeable zinc-air batteries by using the as-prepared catalysts as the air-cathode. The $\mathrm{Co} / \mathrm{N}$-doped catalyst-based battery exhibits a high power density and long-term stability, demonstrating the potential of the catalysts in real application.

\section{Experimental Section}

\subsection{Synthesis of ZnO@ZIF-67 core/shell nanoparticles}

In a typical synthesis of ZnO@ZIF-67 core/shell NPs, 0.1 g ZnO and $1.0 \mathrm{~g} \mathrm{Co}\left(\mathrm{NO}_{3}\right)_{2}$ were dispersed into $70 \mathrm{~mL}$ methanol followed by a continuous stir for half an hour. Then, the resulting solution was mixed with another $70 \mathrm{~mL}$ methanolic solution of 2-Methylimidazole (2.23 g). Continuous stir was kept for 3-5 hours under room temperature. The asprepared purple powder was collected by filtration and was washed by methanol for several times, and the purple powder was further dried in an oven for $\sim 12$ hours.

\subsection{Synthesis of Carbon-ZNC bifunctional catalysts}

The ZnO@ZIF-67 particles $(0.2 \mathrm{~g})$ and melamine/glucose $(1 \mathrm{~g} / 1 \mathrm{~g})$ were dispersed in a solution of $150 \mathrm{ml}$ methanol. The mixture was kept at room temperature for $12 \mathrm{~h}$ under continuous stirring. The purple precipitation was collected by filtration, washed with methanol for several times and dried at $60^{\circ} \mathrm{C}(\sim 12 \mathrm{~h})$. The as-prepared powder was dispersed in a ceramic boat, heated to $300^{\circ} \mathrm{C}$ and maintained for $2 \mathrm{~h}$ in a tube furnace. The temperature in the furnace was further raised to $950^{\circ} \mathrm{C}$ at a ramp rate of $4^{\circ} \mathrm{Cmin}^{-1}$ and kept at that temperature for $2 \mathrm{~h}$. After that, the furnace is cooled down to room temperature naturally. During the pyrolysis process, the furnace is under Ar flow. The asprepared black powder products were collected and marked as CarbonZNC.

\subsection{Characterizations of electrocatalysts}

The structure of the as-prepared bifunctional catalysts was characterized by PXRD, Raman, XPS, ICP, EXAFS and $\mathrm{N}_{2}$ adsorption/desorption

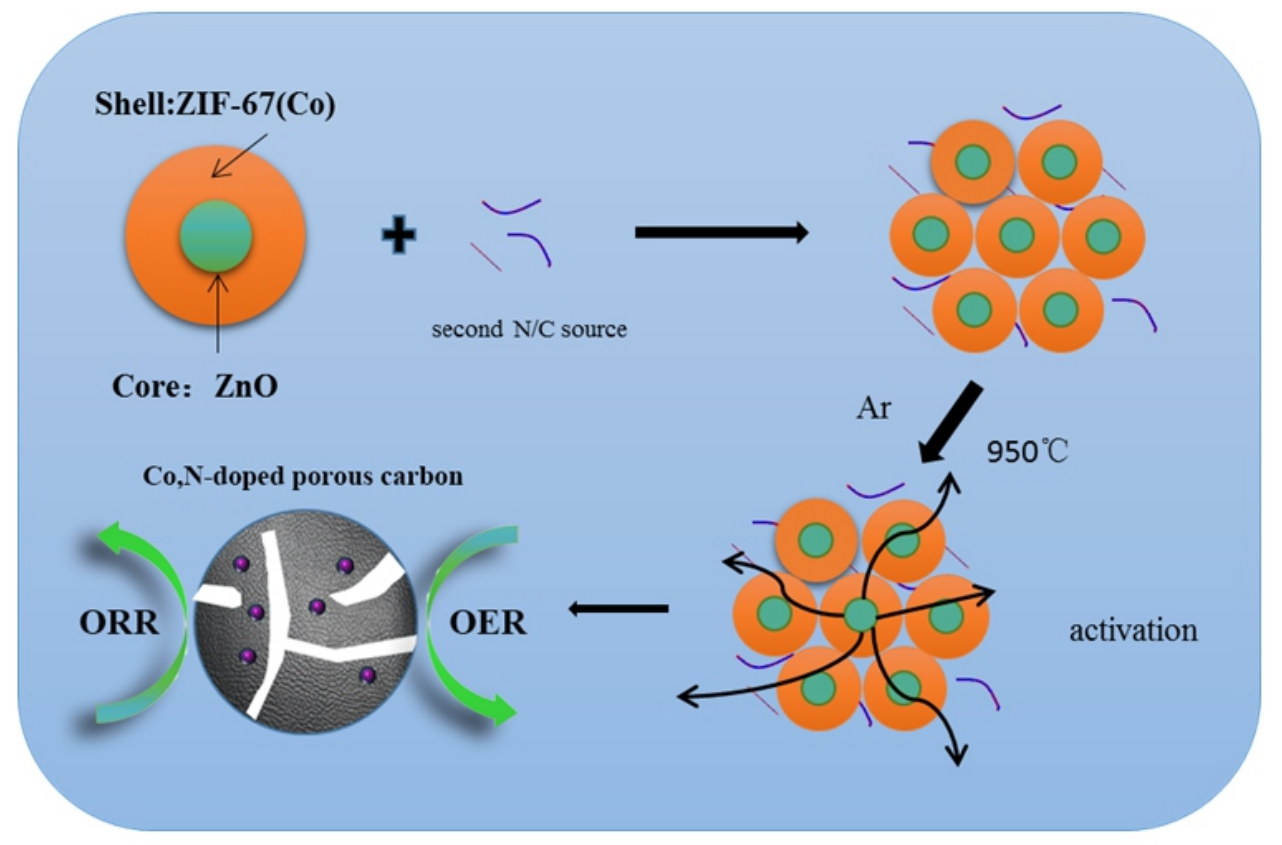

Fig. 1 A core/shell template strategy for synthesis of $\mathrm{Co} / \mathrm{N}$-doped porous carbon catalysts. 
isotherms. The SEM and HRTEM were performed to observe the surface morphology. TGA test was performed to explore the stability of samples. The bifunctional activities of the catalysts were characterized through standard three-electrode cell test controlled by a CHI760e electrochemistry workstation. The ORR tests were performed in $0.1 \mathrm{M}$ $\mathrm{KOH}$. The OER performance was obtained using a RDE in $1 \mathrm{M} \mathrm{KOH}$ solution, and corrected by iR-compensation. The electron-transfer number (n) was calculated by Koutecky-Levich plots, and the yield percentage of $\mathrm{H}_{2} \mathrm{O}_{2}$ was obtained from rotating ring-disk electrode tests. More details on the structure and electrochemical characterizations were presented in Supporting Information.

\section{Density Functional Calculations 3.1 Computational methods}

The geometry optimization and total energy calculations were performed by using first-principle calculations within the framework of density functional theory (DFT), as implemented in the plane wave set Vienna ab initio Simulation Package (VASP) code.$^{57,58}$ Here, we applied a DFT+U with $\mathrm{U}-\mathrm{J}=3.3 \mathrm{eV}$ to obtain structural and energetic properties of Co (100) surface. The spin-polarization was considered in all calculations. The kinetic energy cut off of $500 \mathrm{eV}$ was chosen for the plane-wave expansion to ensure that the energies converged within 1 $\mathrm{meV} /$ per atom. The calculation details can be also referred to the Supporting Information and our previous publications. ${ }^{59,60}$

\subsection{Computational Models}

Three-dimensional periodical supercells containing single-layer graphene, with a lattice constant of $2.46 \AA$, were used to model the pyridine N-doped graphene nanoribbons, with vacuum set around $15 \AA$ in z-directions, to avoid interaction between slabs. The k-point sampling of the Brillioun zone was obtained using a $5 \times 3 \times 1$ grid with their origin centered at the gamma $(\Gamma)$ point by Monkhorst Pack Scheme. The Co (100) surfaces were investigated by using a symmetric periodic slab model with a $15 \AA$ vacuum region thickness between the slabs in order to eliminate the dipole moment and the surface-surface interaction. The Co (100) surface was modeled with a 5 atom-layer slab, after convergence test of surface energy to $<10 \mathrm{meV} / \AA^{2}$. Top two layers were fully relaxed during structural optimizations while other layers were fixed at the equilibrium lattice positions.

The lattice of $4 \times 2$ supercell of periodic unit for free-standing and $\mathrm{N}$-doped graphene was well matched to that of $4 \times 2$ supercell of Co (100) surface. A Van der Waals (vdW) force correction was performed by the Grimme's DFT-D2 scheme ${ }^{57,61}$ to describe the non-bonding interaction between graphene and Co layer. Due to the large unit cells, a Gamma k-point sampling and a Morkhost pack mesh of k-points $(5 \times 3 \times 1)$ were chosen to sample the two dimensional Brillouin zone for optimizing the geometry and calculating the charge density, respectively.

\section{Results and Discussion}

Fig. $2 \mathrm{a}$ and $2 \mathrm{~b}$ show the SEM and HRTEM images of ZnO/ZIF-67 samples, in which the SEM image shows that the as-prepared ZIF-67 is rhombic dodecahedron NP about $300 \mathrm{~nm}$, while HRTEM image reveals that the $\mathrm{ZnO}$ nanorods were encapsulated by ZIF-67 NPs, indicating the successful formation of core/shell structure (Fig. 2b). The enlarged image shows that the lattice parameter is 0.52 and $0.31 \mathrm{~nm}$, which is in consistent with $\mathrm{ZnO}$ crystalline. The PXRD peaks of the synthesized crystal (Fig. 2c) in the range of $5-40^{\circ}$ and $40-80^{\circ}$ show good agreement with the peaks of simulated $\mathrm{ZIF}-67$ and $\mathrm{ZnO}$, respectively, which further confirms the formation of $\mathrm{ZnO} / \mathrm{ZIF}-67$ core/shell structure.

Thermogravimetric analysis (TGA) of ZnO@ZIF-67 was performed under argon flowing at a heating rate of $10{ }^{\circ} \mathrm{C} \mathrm{min}$ (Fig. 2d), where two-steps weight loss is observed. The first step of weight loss starts at $200{ }^{\circ} \mathrm{C}$ and ends at $600{ }^{\circ} \mathrm{C}$, which is attributed to the removal of free and terminal solvent molecules..$^{62}$ The second step of weight loss at $600{ }^{\circ} \mathrm{C}$ corresponds to the partial decomposition of ZIF-67 frameworks. The TGA curve indicates that the thermal stability of ZnO@ZIF-67 core/shell NPs is as high as $600{ }^{\circ} \mathrm{C}$. High thermal stability is helpful for preventing the loss of $\mathrm{N}$ atoms during pyrolysis process.

As illustrated in Fig. 1, by carbonizing the mixture of second N/C sources (here, they are glucose/melamine) and the $\mathrm{ZnO} / \mathrm{ZIF}-67$ composite at $\mathrm{T}=950{ }^{\circ} \mathrm{C}$ in $\mathrm{Ar}$ atmosphere, we prepared the $\mathrm{Co} / \mathrm{N}$-doped porous carbon, which was marked as Carbon-ZNC. For comparison, we also prepared another sample (marked as Carbon-Z1) by directly carbonizing ZnO/ZIF-67 NPs without the addition of glucose/melamine. Fig. 3a-3c show the SEM and HRTEM images of the as-prepared Carbon-ZNC, while the SEM and TEM images of Carbon-Z1 were shown in Fig. S1-S2. Fig. 3a shows that the as-prepared Carbon-ZNC is spherical geometry, and the partial carbon nanotubes with diameter of several nanometers were found on the surface of the Carbon-ZNC (Fig. $3 b)$, while no carbon nanotubes were found in the Carbon-Z1 which means that the addition of second N/C source affects the morphology of the porous carbons and promotes the formation of CNTs. Moreover, we also observed the existence of NPs with sizes around $20 \mathrm{~nm}$ in Carbon$\mathrm{ZNC}$ in Fig. 3b. The enlarged HRTEM image in Fig. 3c shows the well-defined (111) lattice fringes of Co $(0.202 \mathrm{~nm})$, an evidence indicating that these NPs are possibly metallic Co clusters. Fig. 3c also further reveals that the NPs (black dots) are wrapped by graphitic carbons (gray matrix) with the spacing of $0.33 \mathrm{~nm}$, corresponding to the (002) diffraction plane of graphite. As mentioned in previous investigations, Co NPs are encapsulated by a few-layered carbon shell makes it hard for Co species to aggregate ${ }^{63}$. The existence of Co could also be proved by the PXRD, X-ray photoelectron spectroscopy (XPS) and extended X-ray adsorption fine structure (EXAFS). As shown in the PXRD patterns (Fig. 3d), the peak around $26^{\circ}$ corresponds to carbon (002) plane, and the peaks around $44.2^{\circ}, 51.5^{\circ}$ and $75.8^{\circ}$ correspond to Co(111), (200) and (220) planes, respectively. It should be mentioned that no diffraction peaks of $\mathrm{Zn}$ impurities were observed in the PXRD spectra of the Carbon-ZNC sample, because $\mathrm{Zn}$ was evaporated as activating agent at high temperature $\mathrm{T}=950{ }^{\circ} \mathrm{C}\left(>908{ }^{\circ} \mathrm{C}\right.$, boiling point of $\mathrm{Zn}$ ). Several peaks among $200-800 \mathrm{eV}$ in the XPS spectra corresponds to $\mathrm{C} 1 \mathrm{~s}, \mathrm{O} 1 \mathrm{~s}, \mathrm{~N} 1 \mathrm{~s}$ and $\mathrm{Co} 2 \mathrm{p}$, respectively (Fig. 3e). Moreover, Fig. 3f also shows the high-resolution XPS spectra containing two peaks of Co $2 \mathrm{p}_{1 / 2}$ at $795.7 \mathrm{eV}$ and $\mathrm{Co} 2 \mathrm{p}_{32}$ at $780.3 \mathrm{eV}^{64}$ For a $\mathrm{Co} / \mathrm{N}$-doped carbon, the analysis of different nitrogen species is rather essential to identify the active sites in the ORR process. Recently, Guo and coworkers found that the ORR active sites are carbon atoms with Lewis basicity next to pyridinic $\mathrm{N}^{50,65}$ The high resolution $\mathrm{N} 1 \mathrm{~s}$ spectra of Carbon-ZNC were fitted with three different signals of binding energies of $398.4 \pm 0.2,4000.2$ and $4010.2 \mathrm{eV}$, corresponding to pyridinic N, pyrrolic $\mathrm{N}$ and graphitic N, respectively (Fig. 3g). The ratios of the three $\mathrm{N}$ configurations in Carbon-ZNC and Carbon-Z1 were shown in Fig. S3-5 and Table S1, where the contents of nitrogen in the surfaces of Carbon-Z1 and Carbon-ZNC are $2.13 \mathrm{at} \%$ and 1.61 at $\%$. Importantly, the relative ratio of pyridinic $\mathrm{N}$ in the $\mathrm{N}$ configurations of Carbon-ZNC (40\%) is largely higher than that of Carbon-Z1 $(19.3 \%)$. Therefore, the total content $(0.64$ at $\%)$ of pyridinic $\mathrm{N}$ in the surfaces of Carbon-ZNC is also significantly higher than that $(0.41 \mathrm{at} \%)$ of Carbon-Z1. This observation indicates that Carbon-ZNC may hold more active sites, and introduction of glucose/melamine is beneficial for the formation of pyridinic $\mathrm{N}$. The content of $\mathrm{C}, \mathrm{N}, \mathrm{O}$ and Co element is 
also listed in Table S1.

X-ray adsorption spectroscopy at Co k-edge was conducted to better understand the coordination environment of Co atoms. As shown in Fig. 3h, the Co k-edge curves of Carbon-ZNC and Carbon-Z1 are quite similar to that of Co foil, which confirms the fact that the NPs in Carbon-ZNC are metallic Co. However, the Co k-edge of Carbon-ZNC and Carbon-Z1 was shifted to slightly higher energy than Co foil in the range of 7710-7715 eV (Fig. 3h), suggesting the existence of Co-N bonds and the electron transfer from Co to N. ${ }^{66,67}$ Fig. 3i was the Fourier-transformed EXAFS spectra of Carbon-ZNC and Carbon-Z1 derived from Fig. $3 \mathrm{~h}$. A small peak around $1.4 \AA$ corresponding Co-N bond could be observed, confirming the existence of Co-N coordination. The main peaks of three samples around $2.2 \AA$ corresponding Co-Co bond exactly overlap, which re-confirms that the
NPs in Carbon-ZNC are Co clusters. The fitting curves and data are shown in Table S2. Furthermore, the TEM elemental mapping image of Carbon-ZNC was shown in Fig. S6, where a uniform distribution of $\mathrm{N}$ and $\mathrm{Co}$ atoms was observed, suggesting the bonding of Co with the neighboring $\mathrm{N}$ atoms. ${ }^{68,69}$

Fig. 3j shows the Raman spectra of Carbon-ZNC and Carbon-Z1, where $\mathrm{D}$ and $\mathrm{G}$ bands are located at $1350 \mathrm{~cm}^{-1}$ and $1590 \mathrm{~cm}^{-1}$. D band is from the disordered carbon structures and $\mathrm{G}$ band is from the vibration mode to the movement in opposite directions of two carbon atoms in a single graphene sheet. ${ }^{70}$ The relative ratios of the $\mathrm{G}$ band to the $\mathrm{D}$ band illustrate the degree of graphitization. The ratio $\mathrm{I}_{\mathrm{D}} / \mathrm{I}_{\mathrm{G}}$ of Carbon- $\mathrm{Z} 1$ and Carbon-ZNC decreases from 1.07 to 0.86 , indicating that Carbon-ZNC has high graphitization degree. The high graphitization degree of Carbon-ZNC could be partially attributed to the formation of CNTs,
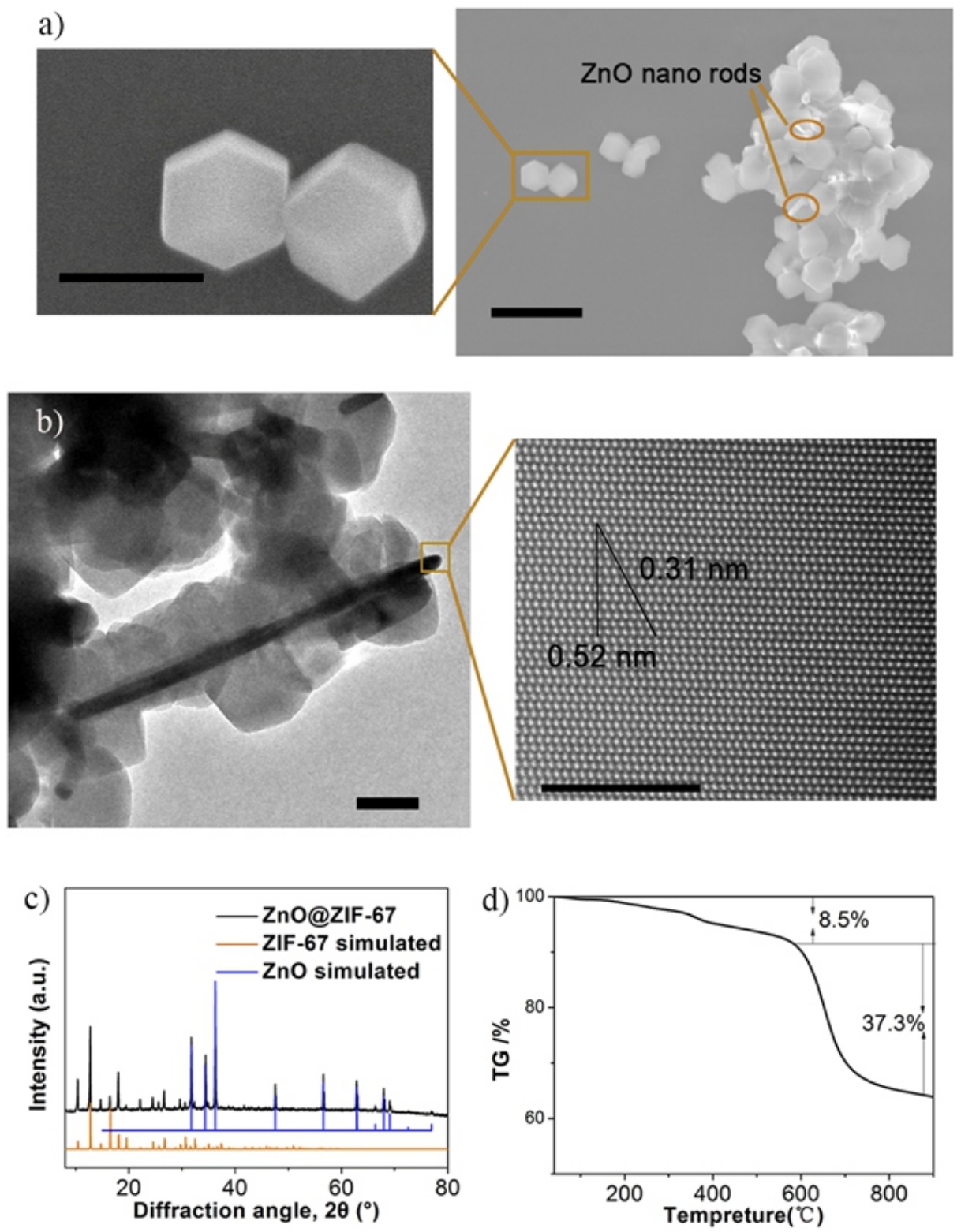

Fig. 2 Morphology and structural characterization of ZnO@ZIF-67 nanoparticles a) SEM image, b) HRTEM image, c) PXRD graph, d) TGA curve. The scale bars are a) $300 \mathrm{~nm}, 1 \mu \mathrm{m}$, b) $200 \mathrm{~nm}, 5 \mathrm{~nm}$. 

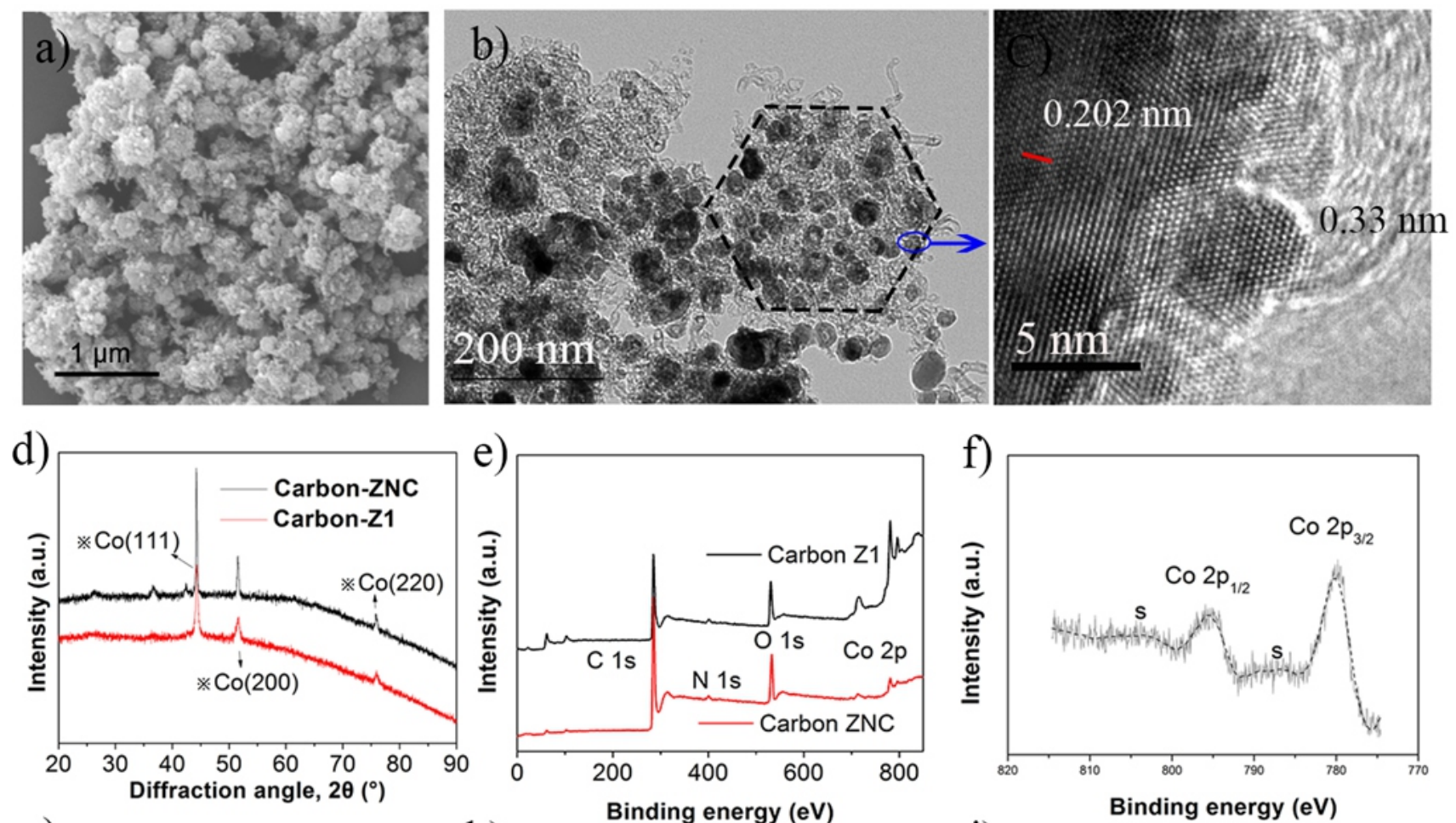

g)

h)
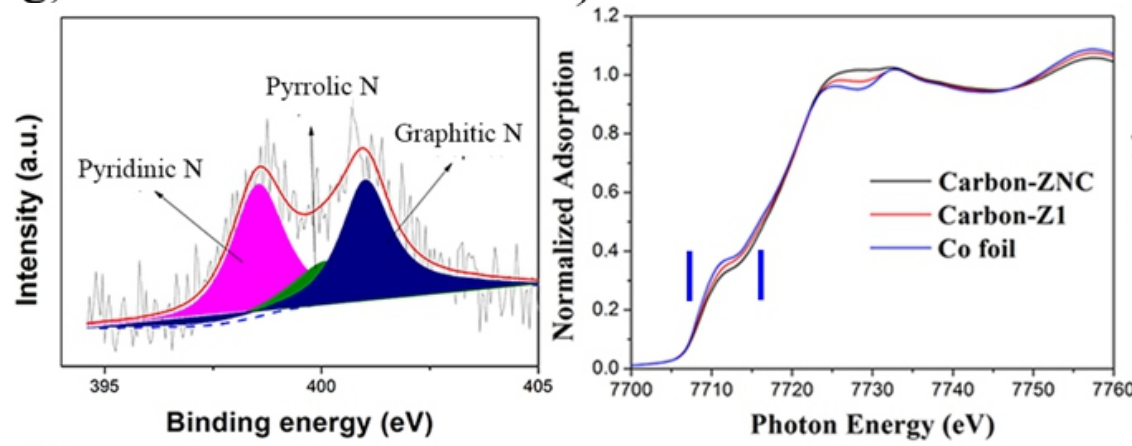

i)

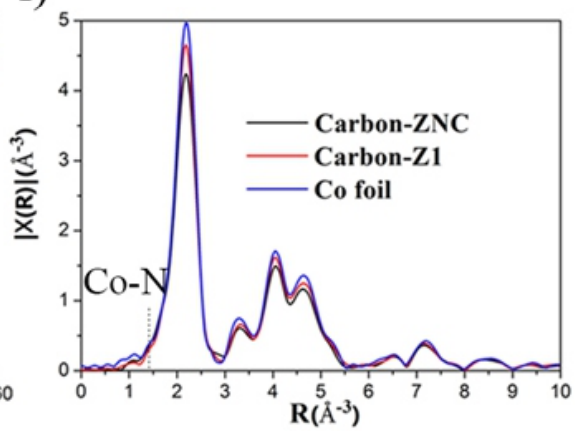

j)

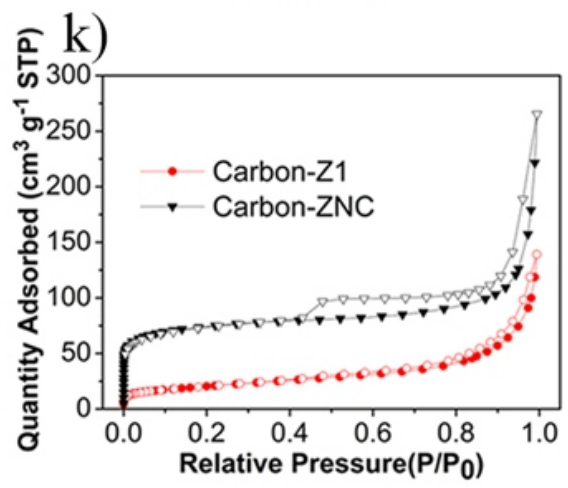

1)
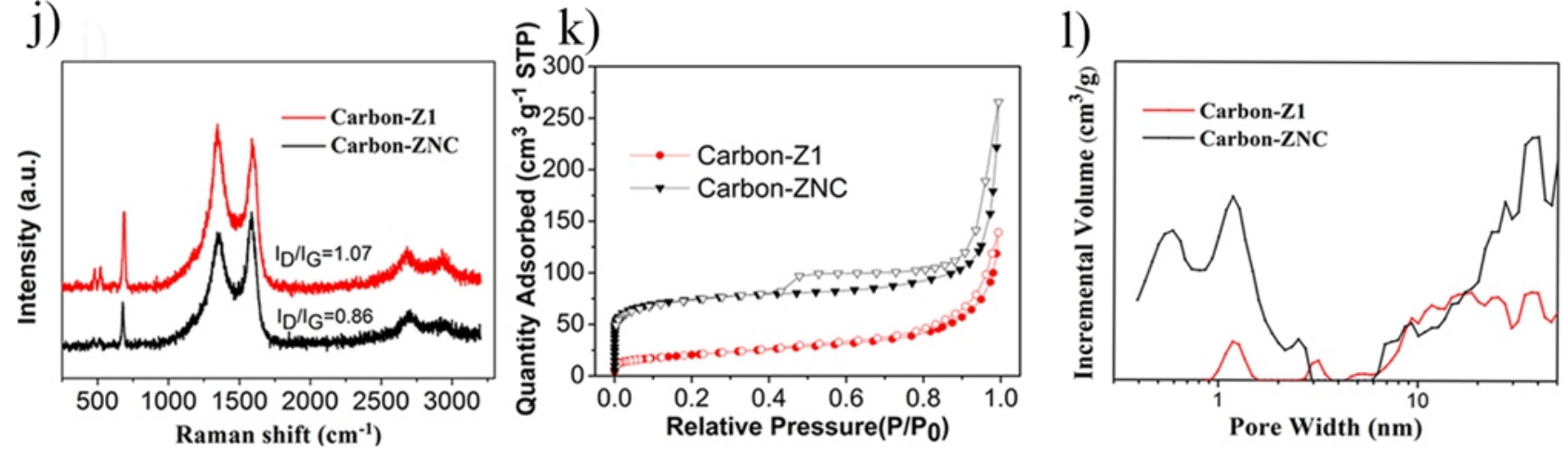

Fig. 3 Morphologies and structural characterizations of the as-synthesized Carbon-ZNC sample. a) SEM image, (b) and (c) HRTEM images at different scale bars, d) PXRD graphs, e) and f) XPS graphs, g) the three types of nitrogen. h) Co K-edge EXAFS spectra of Carbon-ZNC, Carbo-Z1 and Co foil. i) Fourier-transformed Co EXAFS spectra derived from (h). j) Raman spectra, k) adsorption-desorption isotherms of $\mathrm{N}_{2}$ at $77 \mathrm{~K}$ and 1 ) pore-size distribution of Carbon-ZNC and Carbon-Z1. 
a)

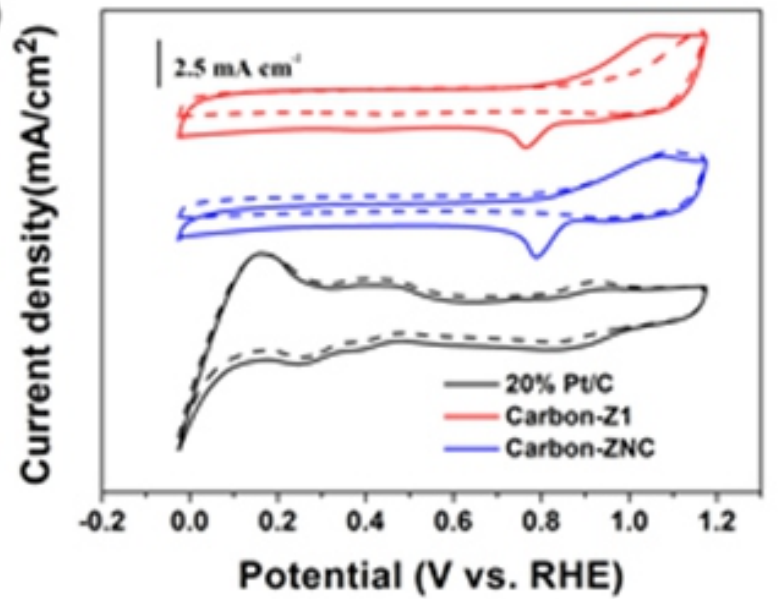

c)

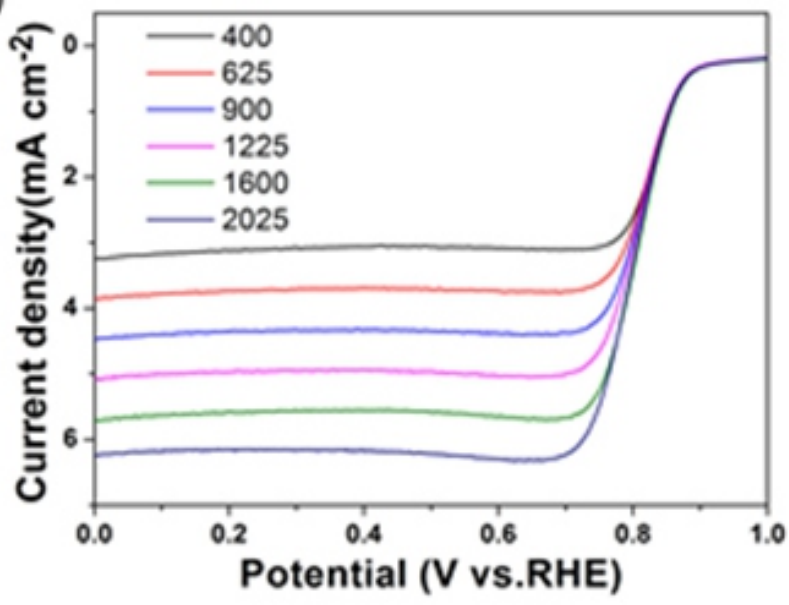

e)

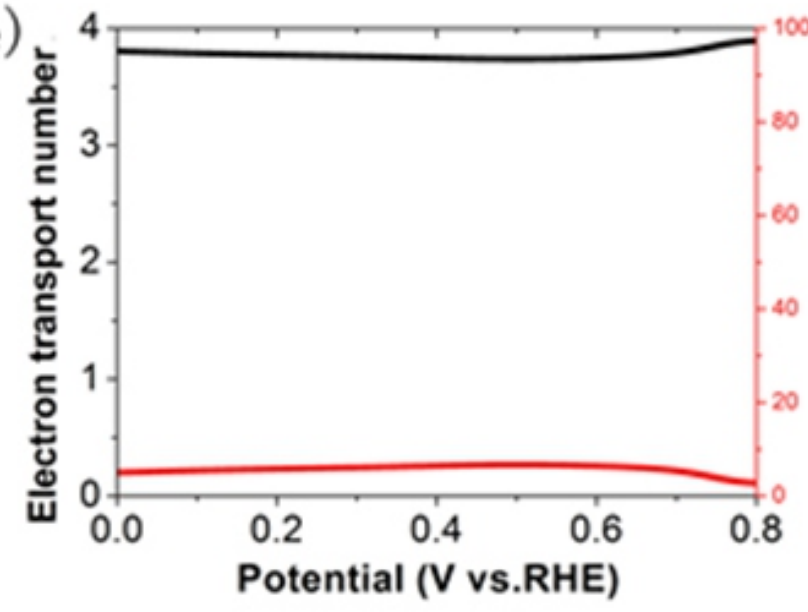

b)

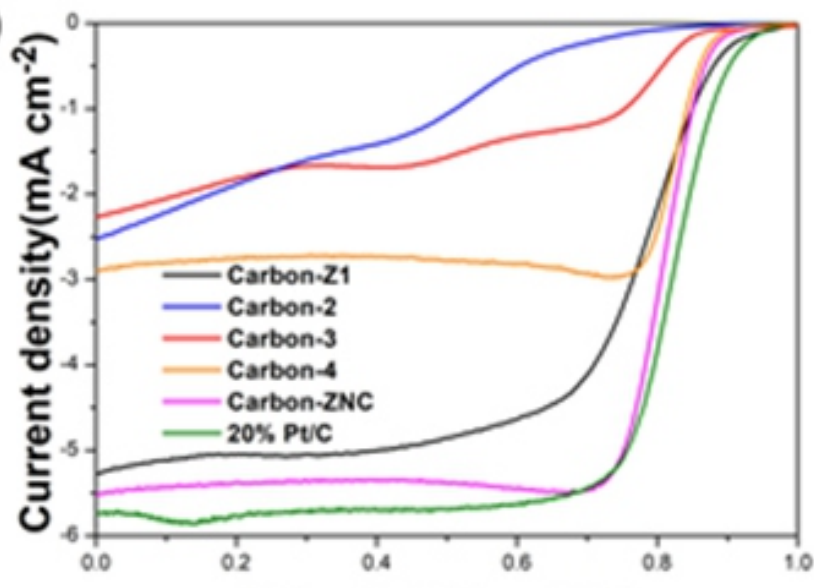

d)
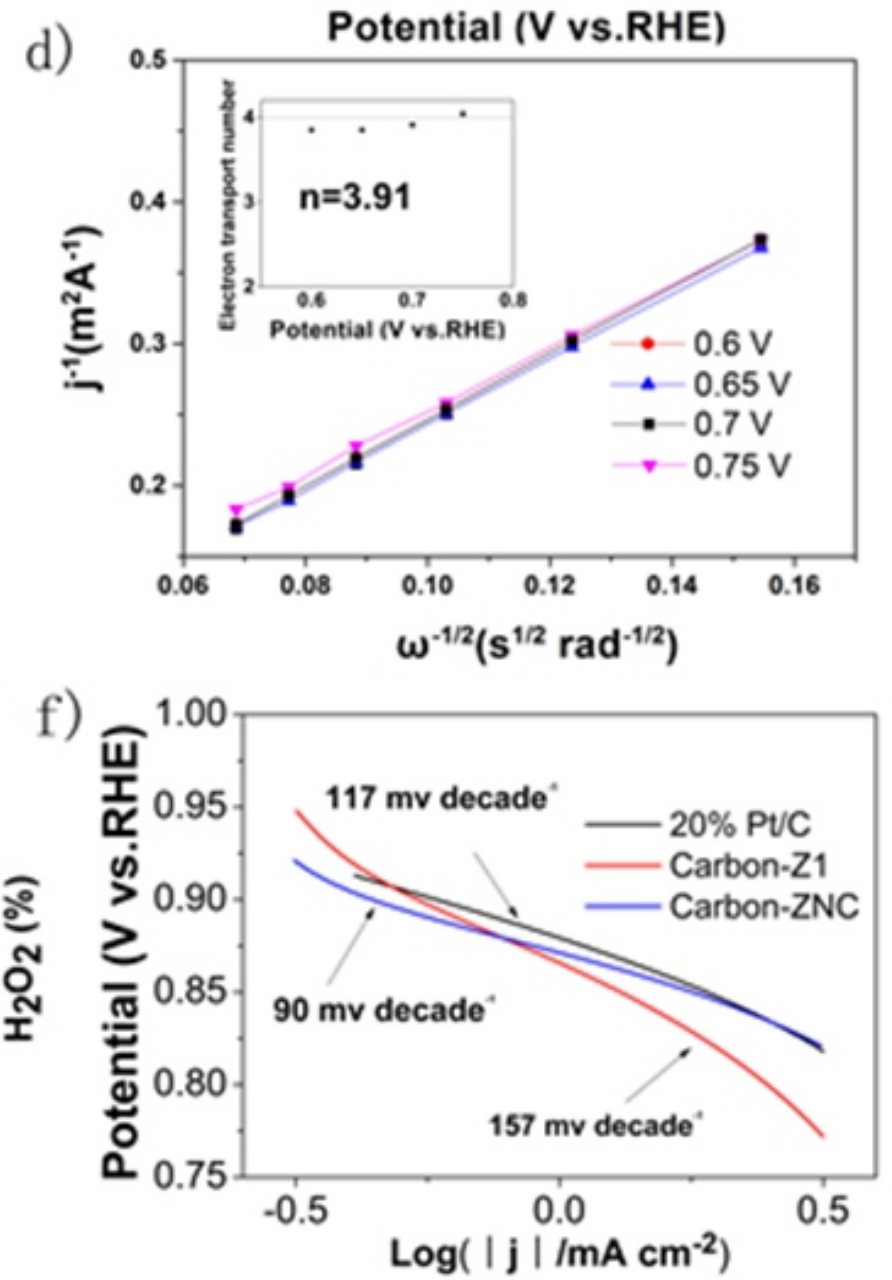

Fig. 4 Electrochemical oxygen reduction activity of the samples. a) CV curves of Carbon-Z1, Carbon-ZNC and commercial $20 \mathrm{wt} \% \mathrm{Pt} / \mathrm{C}$ in $\mathrm{O}_{2}$-saturated (solid line) and $\mathrm{N}_{2}$-saturated (dashed line) $0.1 \mathrm{M} \mathrm{KOH}$ at a sweep rate of $50 \mathrm{mV} \mathrm{s}^{-1}$. b) Linear-sweep voltammograms of Carbon-Z1, Carbon-2, Carbon3, Carbon-4, Carbon-ZNC and commercial $20 \mathrm{wt} \% \mathrm{Pt} / \mathrm{C}$ (all the catalyst loading was about $0.255 \mathrm{mg} \mathrm{cm}^{-2}$ ) in $0.1 \mathrm{M} \mathrm{KOH}$ under oxygen bubbling at a scan rate of $5 \mathrm{mV} \mathrm{s}^{-1}$ and electrode-rotation speed of $1600 \mathrm{rpm}$. c) Rotating-disk voltammograms of Carbon- $\mathrm{ZNC}$ in $\mathrm{O}_{2}$-saturated $0.1 \mathrm{M} \mathrm{KOH}$ with a sweep rate of $5 \mathrm{mV} \mathrm{s}^{-1}$ at the different rotating rates indicated. d) The K-L plots of Carbon-ZNC at the potentials of $0.6 \mathrm{~V}, 0.65 \mathrm{~V}, 0.7 \mathrm{~V}$, and $0.75 \mathrm{~V}$ (vs. RHE). e) The electron number (n) and the production of hydrogen peroxide of Carbon-ZNC in the potential range of 0-0.8 V (vs. RHE). f) Tafel slopes of Carbon-ZNC, Carbon-Z1 and commercial $20 \mathrm{wt} \% \mathrm{Pt} / \mathrm{C}$. 
which can be observed from the TEM image (Fig. 3b). In addition, two small peaks are visible at 2700 and $2950 \mathrm{~cm}^{-1}$, corresponding to $2 \mathrm{D}$ and $\mathrm{D}+\mathrm{D}^{\prime}$ bands of graphite, suggesting the graphite component of several layers rather than a single layer in Carbon-Z1 and Carbon-ZNC. Moreover, the peaks in the Rama spectra at around $680 \mathrm{~cm}^{-1}$ correspond to metallic Co clusters.

As shown in Fig. $3 \mathrm{k}$, the $\mathrm{N}_{2}$ adsorption-desorption isotherm of Carbon-ZNC at $\mathrm{T}=77 \mathrm{~K}$ exhibits a type-IV curve, which suggests the presence of mesopores and micropores. The presence of mesopores and micropores could also be observed through the pore-size distribution of Carbon-ZNC (Fig. 31). The hierarchical pores are favorable for the adsorption and transportation of $\mathrm{O}_{2}$ boosting the ORR activity. ${ }^{63}$ The mesopores and micropores were produced by the gasification of the carbons and high evaporation etching of the $\mathrm{Zn}$ atoms, as mentioned earlier. $\mathrm{N}_{2}$ adsorption-desorption isotherms reveal that adsorption capacity of Carbon-ZNC is remarkably larger than that of Carbon-Z1, due to the addition of second N/C source. Further details on porosity are shown in Table S3.

To explore the electrocatalytic performance of Carbon-ZNC and Carbon-Z1, we performed the cyclic voltammetry (CV), rotating disk electrode (RDE) and rotating ring disk electrode (RRDE) measurements (Fig. 4). As shown in Fig. 4a, only featureless double-layer charging current was observed in $\mathrm{N}_{2}$ saturated $0.1 \mathrm{M} \mathrm{KOH}$ in the potential range from 0 to $1.2 \mathrm{~V}$ vs. reversible hydrogen electrode (RHE). Carbon-ZNC exhibited an apparent cathodic peak at $\sim 0.80 \mathrm{~V}$ in $\mathrm{O}_{2}$ saturated solution, which is slightly higher than that of $20 \mathrm{wt} \% \mathrm{Pt} / \mathrm{C}$. In Fig. $4 \mathrm{~b}$, the current of carbon-ZNC drops rapidly in the potential range of $0.75-0.85$ $\mathrm{V}$ vs. RHE, indicating a kinetic controlled process, while the much more stable current in the potential range of $0-0.7 \mathrm{~V}$ vs. RHE indicates a diffusion-controlled process. The onset potential of Carbon-ZNC is $0.91 \mathrm{~V}$ vs. RHE, which is about $\sim 30 \mathrm{mV}$ lower than that of $20 \%$ commercial Pt/C. However, the half-wave potential of Carbon-ZNC is only $\sim 10 \mathrm{mv}$ lower than $\mathrm{Pt} / \mathrm{C}$ catalyst. These observations indicate that Carbon-ZNC is an excellent electrocatalyst for ORR. On the contrary, Carbon-Z1 shows a relatively larger deviation $\sim 50 \mathrm{mV}$ inferior to Carbon-ZNC and a lower limiting current density. In order to prove the synergistic effects of the core/shell template, we designed three contrast experiments. The first contrast sample (Carbon-2) was derived from secondary N/C source-covered ZIF-67 without $\mathrm{ZnO}$ core. The second one (Carbon-3) was derived from secondary $\mathrm{N} / \mathrm{C}$ source covered $\mathrm{ZnO}$ without ZIF-67 shell, while the third one (Carbon-4) was derived from the physical mixture of $\mathrm{ZnO}$ and $\mathrm{ZIF}-67$ without second N/C sources. The synthesis details of these contrast samples were presented in Supporting Information. The SEM images of Carbon-2 and Carbon-3 are shown in Fig. S7. Actually, all of the three contrast samples show a relatively lower catalytic activity (Fig. $4 \mathrm{~b}$ and Fig. S8-S9), with relatively smaller onset potential and half-wave potential, as well as the limiting current density at the same catalyst loading, compared to Carbon-ZNC catalyst. The observation indicates that the core/shell precursor and the second N/C source can synergistically enhance the ORR catalytic activities. The detailed parameters and curves about electrochemical properties of these catalysts were listed in Table 1 and Fig. S10-14.

Fig. 4c shows the LSV curves of Carbon-ZNC at different rotation rates from 400-2025 rpm. The Koutecky-Levich (K-L) plots of different catalysts calculated from Fig. $4 \mathrm{c}$ at the potentials of $0.6 \mathrm{~V}, 0.65 \mathrm{~V}, 0.7 \mathrm{~V}$, and $0.75 \mathrm{~V}$ are shown in Fig. 4d. The linear K-L curve suggests the first-order reaction kinetics for ORR with respect to the oxygen concentration in the solution. The average electron transfer number of Carbon-ZNC obtained by the RDE measurements is $\sim 3.91$, suggesting a $4 e$ dominated reduction process. Fig. $4 \mathrm{e}$ shows the $\mathrm{H}_{2} \mathrm{O}_{2}$ yields and corresponding electron transfer number of Carbon-ZNC, in which the $\mathrm{H}_{2} \mathrm{O}_{2}$ yield was less than $10 \%$ in the potential range of $0.2 \mathrm{~V}-0.8 \mathrm{~V}$ vs. RHE, and the average electron transfer number $n$ was $c a$. 3.75. Tafel plots were shown in Fig. 4f, in which a slope of $90 \mathrm{mV} \operatorname{dec}^{-1}$ was observed for Carbon-ZNC, which is lower than that of Carbon-Z1 (157 $\left.\mathrm{mV} \operatorname{dec}^{-1}\right)$ and $20 \mathrm{wt} \% \mathrm{Pt} / \mathrm{C}\left(117 \mathrm{mV} \mathrm{dec}^{-1}\right)$. The similar slope of Carbon-ZNC and $\mathrm{Pt} / \mathrm{C}$ catalysts suggests that Carbon-ZNC might have a similar ORR reaction mechanism with $\mathrm{Pt} / \mathrm{C}$ where the ratedetermining step may be the first electron reduction of oxygen. ${ }^{71}$

Durability is another significant factor for evaluating electrocatalysts. We assessed and compared the durability of Carbon-

Table 1 Summary of the electrochemical properties of catalysts in $\mathrm{O}_{2}$-saturated $0.1 \mathrm{M} \mathrm{KOH}$ electrolyte with a catalyst loading of $255 \mu \mathrm{g} \mathrm{cm}^{-2}$ and a potential window of $1.0 \mathrm{~V}$. (All data are obtained via LSV at a rotational speed of $1600 \mathrm{rpm}$, the calculation formula is presented in the Supplementary note 1)

\begin{tabular}{|c|c|c|c|}
\hline Electrocatalyst & $\begin{array}{c}\text { Onset Potential } \\
\text { (V vs. RHE) }\end{array}$ & $\begin{array}{l}\text { Limiting current } \\
\text { Density }\left(\mathrm{mAcm}^{-2}\right)\end{array}$ & $\begin{array}{c}\text { Half- wave potential } \\
\text { vs. RHE) }\end{array}$ \\
\hline Carbon -Z1 & 0.91 & 5.29 & 0.79 \\
\hline Carbon -2 & 0.87 & 2.3 & 0.78 \\
\hline Carbon -3 & 0.75 & 2.6 & 0.57 \\
\hline Carbon -ZNC & 0.91 & 5.52 & 0.81 \\
\hline $20 \mathrm{wt} \% \mathrm{Pt} / \mathrm{C}$ & 0.94 & 5.75 & 0.83 \\
\hline
\end{tabular}



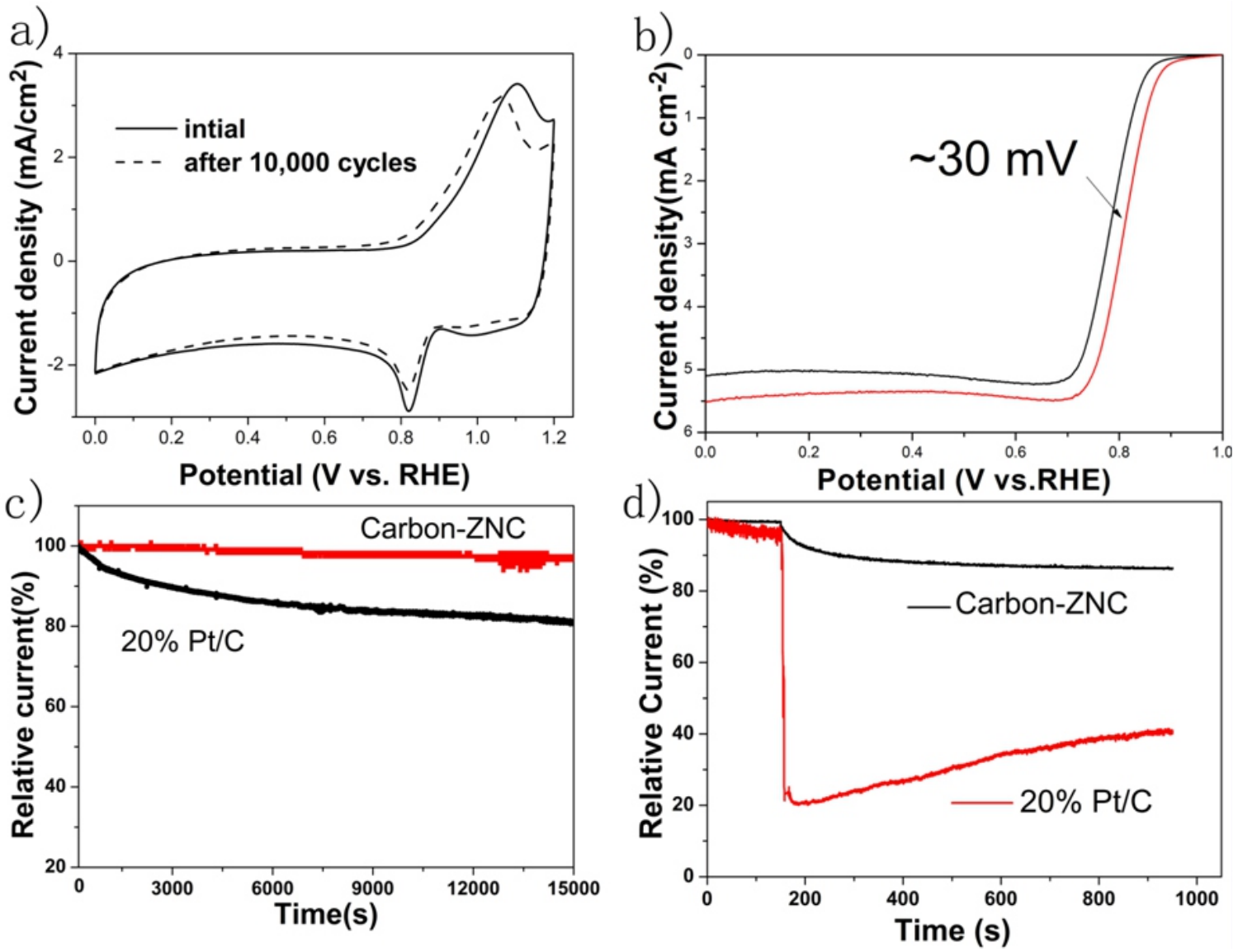

Fig. 5 Electrochemical methanol tolerance and durability of Carbon-ZNC a) CVs of the Carbon-ZNC electrode in oxygen-saturated $0.1 \mathrm{M}$ KOH before and after a continuous potentiodynamic sweep for 10,000 cycles at room temperature with a scan rate of 50 mv s $\mathrm{s}^{-1}$; b) Linear-sweep voltammograms of Carbon-ZNC in $0.1 \mathrm{M} \mathrm{KOH}$ under oxygen bubbling at a scan rate of $5 \mathrm{mV} \mathrm{s}^{-1}$ and electrode-rotation speed of $1600 \mathrm{rpm}$ before and after a continuous potentiodynamic sweep for $10,000 \mathrm{cv}$ cycles. c) Current-time (i-t) chronoamperometric response of Carbon-ZNC and commercial $20 \mathrm{wt} \% \mathrm{Pt} / \mathrm{C}$ electrodes at $0.4 \mathrm{~V}$ (vs. RHE) in $\mathrm{O}_{2}$ saturated $0.1 \mathrm{M} \mathrm{KOH}$ at a rotation rate of $1600 \mathrm{rpm}$; d) current-time (i-t) chronoamperometric response of Carbon$\mathrm{ZNC}$ and $20 \mathrm{wt} \% \mathrm{Pt} / \mathrm{C}$ electrodes by adding $3 \mathrm{ml}$ methanol at about $150 \mathrm{~s}$.
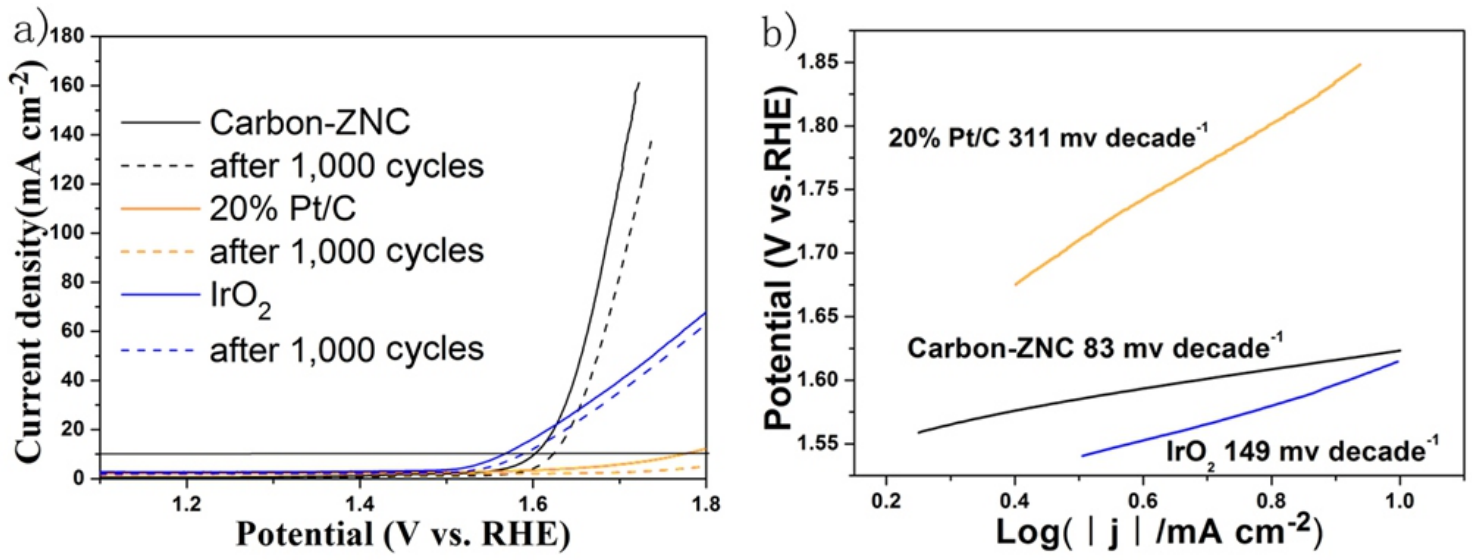

Fig. 6 Electrochemical oxygen evolution activity of Carbon-ZNC a) Linear-sweep voltammograms of Carbon- $\mathrm{ZNC}, \mathrm{IrO}_{2}$ and $20 \mathrm{wt} \% \mathrm{Pt} / \mathrm{C}$ in $1 \mathrm{M} \mathrm{KOH}$ under oxygen bubbling at a scan rate of $5 \mathrm{mV} \mathrm{s}^{-1}$ before and after a continuous potentiodynamic sweep for 1,000 cycles. b) Tafel slopes of Carbon-ZNC, $\mathrm{IrO}_{2}$ and $20 \mathrm{wt} \% \mathrm{Pt} / \mathrm{C}$. 
ZNC and commercial $20 \mathrm{wt} \% \mathrm{Pt} / \mathrm{C}$ catalysts by continuous potential cycling and chronoamperometric measurements at $0.6 \mathrm{~V}$ (vs. RHE) in an $\mathrm{O}_{2}$-saturated $0.1 \mathrm{M} \mathrm{KOH}$ solution at a rotation rate of $1600 \mathrm{rpm}$. As shown in Fig. 5a, the current curve of Carbon-ZNC shows slight changes with the original one after 10,000 cycles. Moreover, the halfwave potential $\mathrm{E}_{1 / 2}$ of the Carbon-ZNC electrode exhibited a negative shift of only $\sim 30 \mathrm{mV}$ after 10,000 cycles (Fig. 5b). After 15,000s of continuous chronoamperometric measurements, the current density of Carbon-ZNC catalysts exhibited a decrease no more than 5\%, compared to the original value, whereas the decrease of commercial $20 \mathrm{wt} \% \mathrm{Pt} / \mathrm{C}$ catalysts was $\sim 20 \%$ in the same conditions (Fig. 5c). To test the resistance of the catalysts to methanol crossover effect, $3 \mathrm{ml}$ of methanol was added into $\mathrm{O}_{2}$-saturrated $0.1 \mathrm{M} \mathrm{KOH}$. The voltammetric current of Carbon-ZNC presents slight decrease while that of $20 \mathrm{wt} \%$ $\mathrm{Pt} / \mathrm{C}$ decreases to about $20-40 \%$ of original value (Fig. $5 \mathrm{~d}$ ). The excellent stability of the as-prepared Carbon-ZNC may be ascribed to the encapsulation of Co NPs by graphitic carbons, as mentioned earlier.

As described previously, developing a high performance bifunctional electrocatalyst is significantly important. Fig. 6a-b show the electrocatalytic activity of Carbon-ZNC for OER in $\mathrm{O}_{2}$ saturated $1.0 \mathrm{M}$ $\mathrm{KOH}$ solution by LSV experiments with the potential extended to the water oxidation regime. It is very important to compare the overpotentials corresponding to the current density of $10 \mathrm{~mA} \mathrm{~cm}$, which is about $10 \%$ efficiency of solar-to chemical conversion. As shown in Fig. 6a, Carbon-ZNC gives a current of $10 \mathrm{~mA} \mathrm{~cm}^{-2}$ (all the catalyst loadings are $255 \mu \mathrm{g} \mathrm{cm}^{-2}$ ) at a potential of $\sim 1.6 \mathrm{~V}$ vs. RHE, which is comparable with most of the reported $\mathrm{N}$-doped carbons and $\mathrm{IrO}_{2}(\sim 1.57 \mathrm{~V}$ vs. RHE), and apparently better than $20 \mathrm{wt} \% \mathrm{Pt} / \mathrm{C}(\sim 1.8$ $\mathrm{V}$ vs. RHE). Interestingly, Carbon-ZNC exhibits a higher current density than $\mathrm{IrO}_{2}$ at the potential range more than $1.63 \mathrm{~V}$. Moreover, the Tafel slope of Carbon-ZNC ( $83 \mathrm{mV}$ decade $\left.^{-1}\right)$ is smaller than those of $\mathrm{IrO}_{2}\left(149 \mathrm{mV}\right.$ decade $\left.{ }^{-1}\right)$ and commercial $20 \mathrm{wt} \% \mathrm{Pt} / \mathrm{C}\left(311 \mathrm{mV}\right.$ decade $\left.{ }^{-1}\right)$ (Fig. 6b), indicating that Carbon-ZNC possesses a comparable OER activity with $\mathrm{IrO}_{2}$, and better OER activity than $20 \mathrm{wt} \% \mathrm{Pt} / \mathrm{C}$. The durability of a catalyst is significant in practical applications. So, the stability test was conducted with continuous scans at a sweep rate of $200 \mathrm{mV} \mathrm{s}^{-1}$. A variation of $30 \mathrm{mV}$ was observed for Carbon-ZNC after 1000 cycles (dash line in Fig. 6a), indicating that Carbon-ZNC is also very stable in the OER process. All the results indicate that Carbon$\mathrm{ZNC}$ is an excellent bifunctional catalyst for both ORR and OER.

In order to unveil the origin of highly enhanced bifunctional catalytic activity of Carbon-ZNC for ORR and OER, we employed DFT to investigate the ORR/OER mechanism of Co-based carbon systems. Previous experimental characterizations have shown that Co was encapsulated by $\mathrm{N}$-doped carbon nanosheets (Fig. 3b-c), and Co (100) was a representative crystal face as shown in XRD spectra (Fig. 3d). The EXAFS spectra also revealed the coordination of Co and $\mathrm{N}$ atoms (Fig. 3h and 3i). Therefore, we used the model of pyridine Ndoped (pdN-doped) graphene supported on Co (100) as a simplification of the experimental Carbon-ZNC sample, because pdN-doped graphene has been reported as more active center than pyrrole $\mathrm{N}$-doped graphene. ${ }^{65}$ For comparison, the free-standing pdN-doped graphene is also considered by DFT calculations. Each model studied here was shown in Fig. S15. The details on the theoretical calculations and elementary steps of the ORR and OER electrocatalysis were presented in Supporting Information.

The free energy diagrams of different catalysts reflecting the calculated on-set potential and overpotential ( $\eta^{\text {ORR }}$ and $\eta^{\text {OER }}$ ) for ORR and OER have been systematically studied (the detailed analysis and data were shown in Supporting Information, Table S4-7) according to electrochemical frameworks developed by Nørskov and co-workers. ${ }^{72-74}$
The free energy diagrams of the free-standing and Co-supported pdN-doped graphenes for ORR were shown in Fig. 7a and S16a. For the ORR on Co-supported pdN-doped graphene, all the reaction steps are exothermic at zero potential $(\mathrm{U}=\mathrm{O})$. At an equilibrium potential of $1.23 \mathrm{~V}$, the first and last reaction steps are also exothermic. Until the potential changed to $0.56 \mathrm{~V}$, the free energies for all steps run upward, meaning that about $0.56 \mathrm{~V}$ is the ORR on-set potential of Co-supported pdN-doped graphene. Meanwhile, the reaction step of $\mathrm{O}^{*}$ to $\mathrm{OH}^{*}$ is the potential-determining step of ORR on Co-supported pdN-doped graphene (Fig. 7a). On the other hand, the on-set potential of ORR on the free-standing pdN-doped graphene is reduced to be $-0.24 \mathrm{~V}$, as illustrated by Fig. S16a. Thus, compared with the equilibrium potential, about $0.67 \mathrm{~V}$ and $1.47 \mathrm{~V}$ overpotentials are needed for the Co-supported and free-standing pdN-doped graphenes in the ORR process, respectively.

Fig. $7 \mathrm{~b}$ and $\mathrm{S} 16 \mathrm{~b}$ give the free energies of various intermediates for the OER process catalyzed by the free-standing and Co-supported pdN-doped graphene at different constant potentials, respectively. As shown in Fig. 7b, at equilibrium potential of $0 \mathrm{~V}$, all the reaction steps are endothermic while at $1.23 \mathrm{~V}$, only the first step is endothermic. Until the potential increases to $2.09 \mathrm{~V}$, the free energies for all the reaction steps run downhill. Therefore, the on-set potential is about $2.09 \mathrm{~V}$ and the potential-determining step is the reaction step of $\mathrm{OH}^{-}$to $\mathrm{OH}^{*}$ on Cosupported pdN graphene. Similarly, for free-standing $\mathrm{pdN}$ graphene, as shown in the Fig. S16b, when the potential increases to $4.33 \mathrm{~V}$, the free energies of the all steps would run downhill. These results indicate that about $0.86 \mathrm{~V}$ and $3.10 \mathrm{~V}$ are needed for the OER process on Cosupported and free-standing pdN-doped graphenes, corresponding to the equilibrium potential. For comparison, $\mathrm{Pt}$ (111) and $\mathrm{IrO}_{2}$ (110), two commonly used reference electrocatalyst in experiments, were also considered as the models of commercial $\mathrm{Pt} / \mathrm{C}$ and $\mathrm{IrO}_{2}$. Fig. $\mathrm{S} 17$ shows the free energy diagrams of the ORR on ideal catalyst and Pt (111) surface and the OER on ideal catalyst and $\mathrm{IrO}_{2}(110)$ at zero electrode potential, on-set electrode potential and equilibrium potential, respectively. We compared the calculated ORR and OER on-set potentials with experimental results (see Fig. 7c-d), in which the order of catalytic activities of different samples from the theoretical calculations qualitatively agrees the ones from the experimental measurements (the experimentally measured values of Carbon-ZNC, $\mathrm{Pt} / \mathrm{C}$ and $\mathrm{IrO}_{2}$ are taken from Fig. 4 and Fig. 6), indicating that our theoretical model is able to reproduce the order of the catalytic activities of the catalysts (i.e. qualitative agreement). The reasons for the quantitative disagreement between theoretical value and experimental result may be that theoretical value is from the well-defined catalyst model while the experimental result is from the nanoparticle sample. Actually, with the addition of the $\mathrm{Co}$, the performance of $\mathrm{pdN}$ in ORR and OER processes would be improved greatly. That is, the Cosupported pdN-doped graphene is an excellent candidate for the ORR and OER.

To gain further insight of the shift of the catalytic performance, three-dimensional charge density difference plots were calculated by subtracting electronic charge of free-standing pdN-doped and the pdNdoped graphene/Co (100), as shown in Fig. 7e and 7f. Obviously, there is significant electron coupling at the graphene-Co interface, and the electronic properties of the pdN-graphene would be significantly altered by the electron transferring from Co to pdN-doped graphene. The electron charge transfer from Co top surface to $\mathrm{pdN}$-doped graphene would result in the conversion of the $\mathrm{N}$-doped carbon to a bifunctional catalyst for ORR/OER as mentioned above. The theoretical calculations also suggest that N-doped carbon encapsulating an electrophilic component may be a high-performance bifunctional catalyst candidate, 
which provides a useful strategy for design of high-performance nonprecious metal catalysts for the ORR/OER.

Based on the structural and compositional characterizations of Carbon-ZNC, we believe that three important aspects should be responsible for its superior ORR/OER activity and stability: (1) The sufficient exposure of active sites can be ascribed to the activation of $\mathrm{Zn}$ vapor during carbonization at $950^{\circ} \mathrm{C}$, and the presence of mesopores are considered helpful to quick mass transfer and smooth diffusion of electrolyte. (2) The addition of N/C source can improve the BET surface area, graphitic degree, conductivity and the content of pyridinic $\mathrm{N}$ of the catalyst. (3) The encapsulated Co NPs provide a unique host-guest electronic system, which are helpful for electroactivity.
To explore the practical application of Carbon-ZNC as bifunctional catalysts in a battery, we assembled a home-made Zn-Air battery with $6 \mathrm{M} \mathrm{KOH}$ and $0.2 \mathrm{M}$ Zinc acetate as the electrolyte, Carbon-ZNC loaded carbon cloth $\left(1 \mathrm{mg} \mathrm{cm}^{-2}\right)$ as the air cathode and a polished zinc plate as the anode, respectively (Fig. 8a). The Zn-air battery with 20 $\mathrm{wt} \% \mathrm{Pt} / \mathrm{C}-\mathrm{IrO}_{2}$ as air cathode was also fabricated for comparison. An open circuit of $1.39 \mathrm{~V}$ was observed for Carbon-ZNC-based battery (Fig. S18). The charging-discharging polarization curves of the Carbon-ZNCbased and $\mathrm{Pt}-\mathrm{IrO}_{2}-$ based batteries are shown in Fig. 8b, where CarbonZNC-based battery shows a superior charging and discharging performance compared to $\mathrm{Pt}-\mathrm{IrO}_{2}$-based one. Furthermore, the overpotential of Carbon-ZNC-based battery for ORR and OER is 1.25 $\mathrm{V}$ at $50 \mathrm{~mA} \mathrm{~cm}{ }^{-2}$ and $1.5 \mathrm{~V}$ at $100 \mathrm{~mA} \mathrm{~cm}$, both much smaller than a)

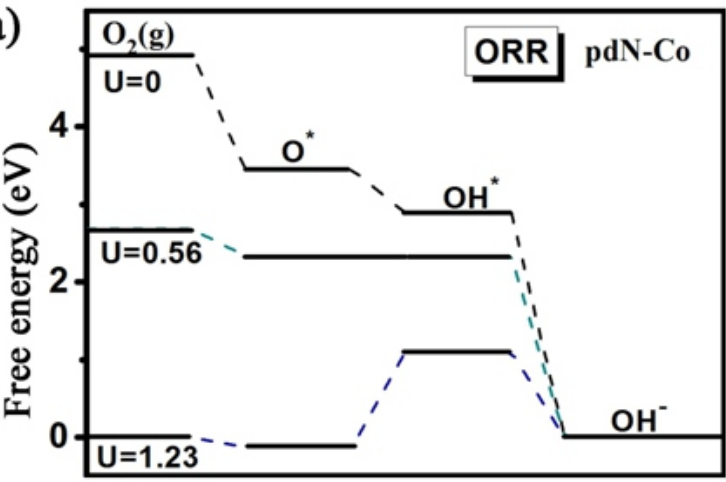

c)

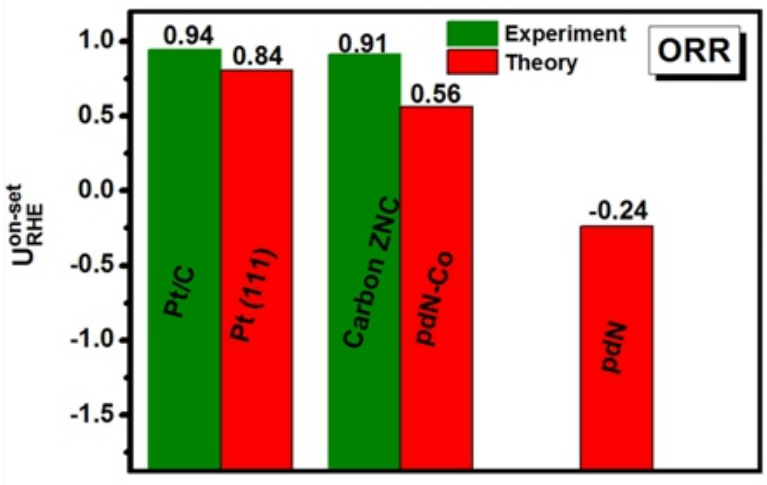

e)

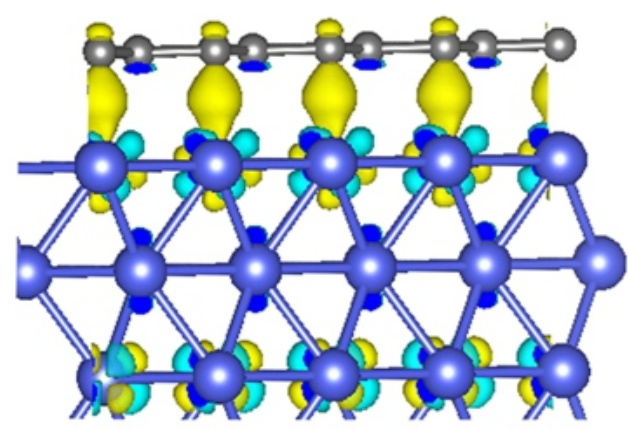

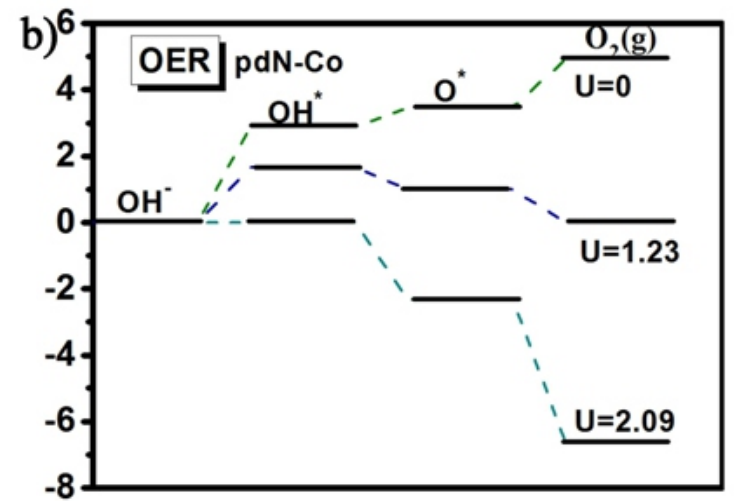

d)

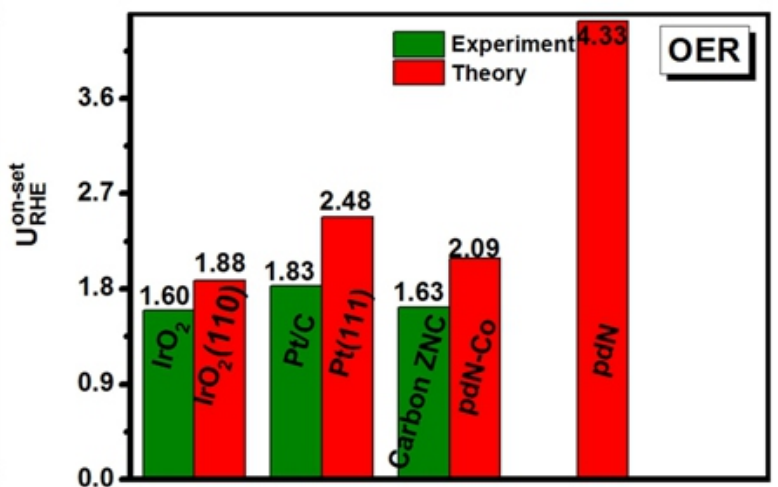

f)

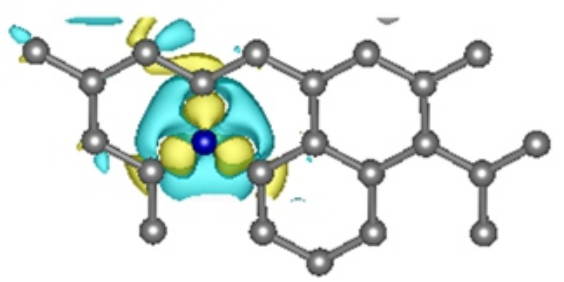

Fig. 7 Free energy diagrams for the a) ORR and b) OER on Co-supported pdN-doped graphene. Comparisons of the on-set potential of different catalysts between theoretical calculations and experiment measurements for (c) ORR and (d) OER. The top or side view of 3D charge density difference plot for the interface between pyridine N-doped graphene and Co (100) layer (e) and the free-standing pdN-doped graphene (f), respectively. Yellow and cyan iso-surfaces represent charge accumulation and depletion in the $3 \mathrm{D}$ space with an iso-surface value of $0.002 \mathrm{e} / \AA^{3}{ }^{3}$ Gray, blue and green balls represent $\mathrm{C}, \mathrm{Co}$ and $\mathrm{N}$ atoms, respectively. 
those of the $\mathrm{Pt}-\mathrm{IrO}_{2}$-based battery. It could be observed that the discharging voltage of Carbon-ZNC-based battery remains a higher value than that of $\mathrm{Pt}-\mathrm{IrO}_{2}$-based one in the range of current density applied. And the power density of Carbon-ZNC-based battery reaches a maximum of $\sim 185 \mathrm{~mW} \mathrm{~cm}^{-2}$ at the current density of $\sim 410 \mathrm{~mA} \mathrm{~cm}$, which is about $16 \%$ higher than that of $\mathrm{Pt}_{-} \mathrm{IrO}_{2}$-based one $(160 \mathrm{~mW} \mathrm{~cm}$ ${ }^{2}$, Fig. 8c) and also comparable with several other results, ${ }^{75-77}$ indicating that Carbon-ZNC is an excellent bifunctional catalyst for $\mathrm{Zn}$-air battery. ${ }^{78-79}$ Moreover, the cycle stability of Carbon-ZNC-based battery was also tested at a current density of $5 \mathrm{~mA} \mathrm{~cm}$.- After $30 \mathrm{~h}$ testing (about 90 cycles), the charging potential rises from $2.13 \mathrm{~V}$ to $2.17 \mathrm{~V}$ and the discharging potential decreases from $1.23 \mathrm{~V}$ to $1.20 \mathrm{~V}$, demonstrating the super long-term stability of Carbon-ZNC-based battery (Fig. 8d). Fig. 8e also shows a blue light-emitting diode lighted by two series $\mathrm{Zn}$-air batteries.

\section{Conclusions}

In summary, we have proposed a core/shell template strategy to synthesize non-precious metal/N-doped porous carbon as efficient and stable bifunctional ORR and OER electrocatalyst for rechargeable Znair battery. In the core/shell structure, the core serves as an activating agent during pyrolysis process and the shell provides the electroactive sites. In particular, we have used the ZnO@ZIF-67 core/shell NP as an example to successfully prepare the $\mathrm{Co} / \mathrm{N}$-doped Carbon-ZNC electrocatalyst. As expected, Carbon-ZNC exhibits similar ORR activity with $20 \% \mathrm{Pt} / \mathrm{C}$ and comparable OER activity with $\mathrm{IrO}_{2}$ in alkaline medium. The superior activities may be attributed to the hierarchical porous structure formed by the self-sacrificial template and the synergistic effect of codoping of Co NPs and N atoms. Moreover, DFT calculations also reveal that the enhanced activity of Carbon-ZNC originates from the electron transferring from the $\mathrm{N}$-doped graphene to Co clusters, which tailors the free energies of reaction intermediates for enhancing the ORR/OER activity. As a result, Zn-air battery with Carbon-ZNC as an efficient air electrode exhibits not only a high power density of $185 \mathrm{~mW} \mathrm{~cm}^{-2}$, but also a long-term stability (30 h, 90 cycles). These findings suggest that high performance electrocatalysts can be designed by rationally encapsulating electrophilic components (say, metallic Co clusters) into N-doped carbons. Overall, the core/shell template synthesis strategy proposed here can be applied in the preparation of other core/shell MOF-derived carbon electrocatalysts and would pave an avenue for the rational design of high-performance and low-cost ORR/OER bifunctional electrocatalysts for $\mathrm{Zn}$-air battery.

\section{Supporting Information}

Synthesis of Carbon-Z1, Carbon-2, Carbon-3, detailed structure and electrochemical characterizations of samples, fabrication details of $\mathrm{Zn}$ air battery, Computational details.

\section{Conflict of Interest}

The authors declare no conflict of interest.
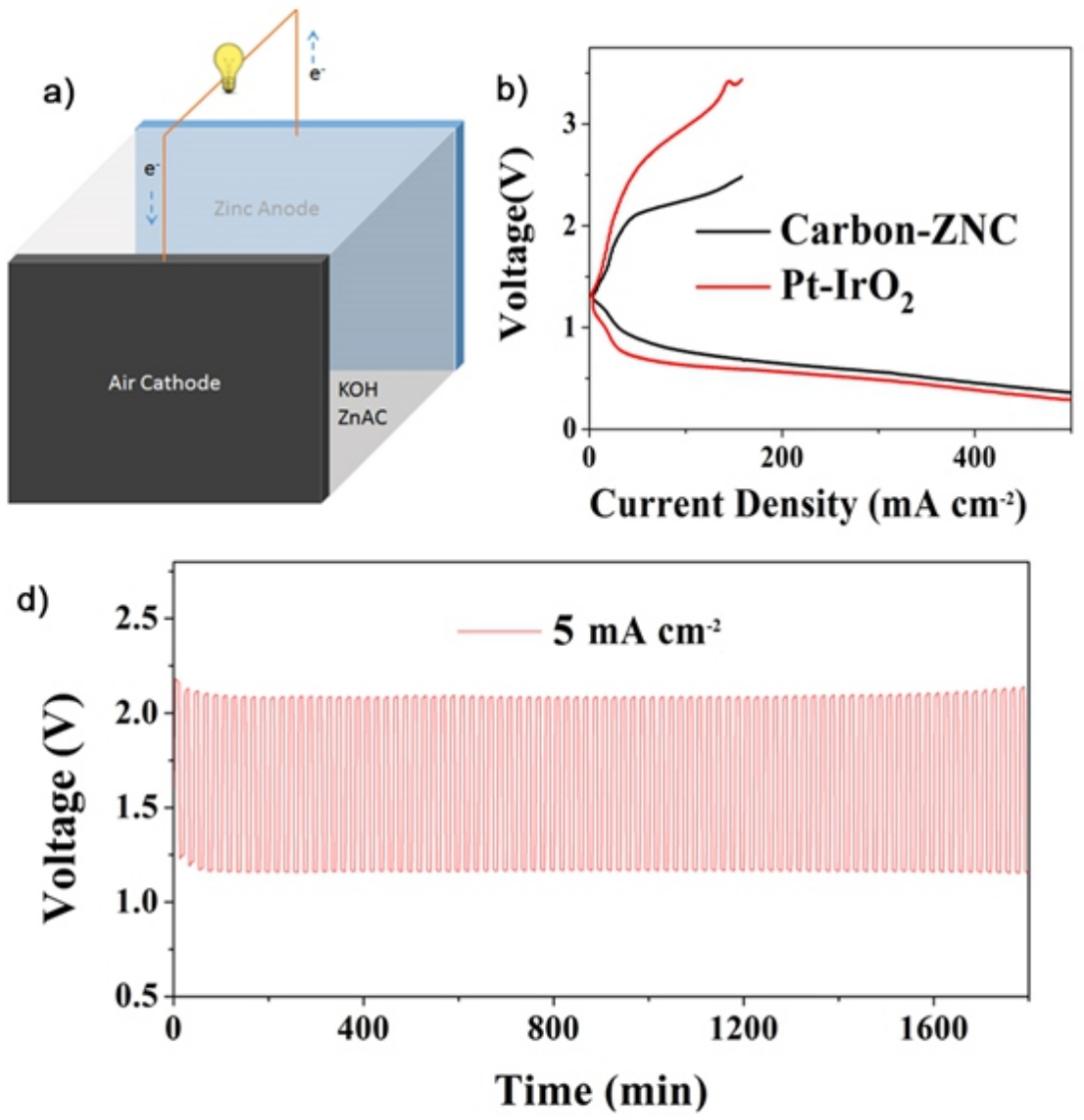

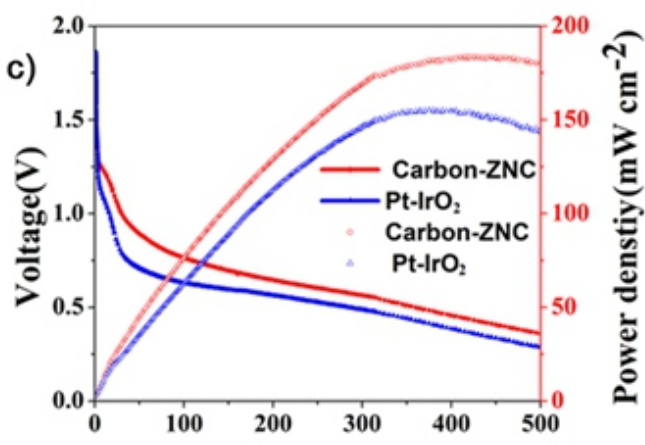

Current density $\left(\mathrm{mA} \mathrm{cm}^{-2}\right)$

e)

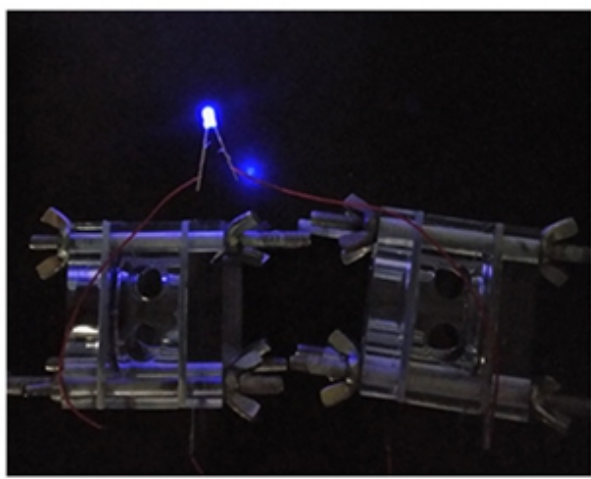

Fig. 8 a) Schematic representation of the rechargeable $\mathrm{Zn}$-air battery. b) Charging-discharging polarization (V-j) curves of Carbon-ZNC and Pt-IrO ${ }_{2}$. c) The discharging curves and peak power density curves of Carbon- $\mathrm{ZNC}$ and $\mathrm{Pt}_{-} \mathrm{IrO}_{2}$ batteries. d) Cycling performance at the charging and discharging current density of Carbon-ZNC at $5 \mathrm{~mA} \mathrm{~cm}^{-2}$. e) Photograph of a blue LED (2.5 V) powered by two $\mathrm{Zn}$-air batteries. 


\section{References}

1. B. C. H. Steele and A. Heinzel, Nature, 2001, 414, 345.

2. T. J. Meyer, Nature, 2008, 451, 778-779.

3. L. Qu, Y. Liu, J. B. Baek and L. Dai, ACS Nano, 2010, 4, 1321-1326.

4. W. Yu, M. D. Porosoff and J. G. Chen, Chem. Rev., 2012, 112, 5780-5817.

5. Z. Gao, Y. Schwab, Y. Zhang, N. Song and X. Li, Adv.Funct. Mater., 2018, 28, 1800563 .

6. Y. Zhang, Z. Gao, N. Song, J. He and X. Li, Mater. Today Energy, 2018, 9, 319-335.

7. Y. Li and H. Dai, Chem. Soc. Rev., 2014, 43, 5257-5275.

8. L. Yang, X. Zeng, D. Wang and D. Cao, Energy Storage Mater, 2018, 12, 277-283.

9. M. Winter and R. J. Brodd, Chem. Rev., 2004, 104, 4245-4269.

10. F. Jiao and H. Frei, Angew. Chem. Int. Ed., 2009, 48, 1841-1844.

11. B. S. Yeo and A. T. Bell, J. Am. Chem. Soc., 2011, 133, 5587-5593.

12. L. Yang, Y. Lv and D. Cao, J. Mater. Chem. A, 2018, 6, 3926-3932.

13. H. Yu, A. Fisher, D. Cheng and D. Cao, ACS Appl. Mater. Int., 2016, 8, 21431-21439

14. B. Dunn, H. Kamath and J. M. Tarascon, Science, 2011, 334, 928-935.

15. J. Suntivich, K. J. May, H. A. Gasteiger, J. B. Goodenough and Y. ShaoHorn, Science, 2011, 334, 1383-1385.

16. F. Cheng and J. Chen, Chem. Soc. Rev., 2012, 41, 2172-2192.

17. L. Yang, X. Zeng, W. Wang and D. Cao, Adv. Funct. Mater, 2018, 28, 1704537.

18. R. Bashyam and P. Zelenay, Nature, 2006, 443, 63-66.

19. G. Wu, K. L. More, C. M. Johnston and P. Zelenay, Science, 2011, 332, 443-447.

20. R. Liu, C. von Malotki, L. Arnold, N. Koshino, H. Higashimura, M. Baumgarten and K. Mullen, J. Am. Chem. Soc., 2011, 133, 10372-10375.

21. Z. Gao, Y. Zhang, N. Song and X. Li, Electrochim. Acta, 2017, 246, 507516.

22. Z. Gao, Y. Zhang, N. Song and X. Li, Mater. Res. Lett., 2017, 5, $69-88$.

23. Y. Zhang, Z. Gao and X. Li, Small, 2017, 13, 1701927.

24. Z. Gao, N. Song, Y. Zhang and X. Li, Nano Lett., 2015, 15, 8194-8203.

25. Z. Gao, N. Song, Y. Zhang, Y. Schwab, J. He and X. Li, ACS Sustain. Chem. Eng., 2018, 6, 11386-11396.

26. H. W. Liang, W. Wei, Z. S. Wu, X. Feng and K. Müllen, J. Am. Chem. Soc., 2013, 135, 16002-16005.

27. Y. Meng, W. Song, H. Huang, Z. Ren, S.-Y. Chen and S. L. Suib, J. Am. Chem. Soc., 2014, 136, 11452-11464.

28. D. Ding, K. Shen, X. Chen, H. Chen, J. Chen, T. Fan, R. Wu and Y. Li, ACS Catal., 2018, 8, 7879-7888.

29. T. Wang, Z. Kou, S. Mu, J. Liu, D. He, I. S. Amiinu, W. Meng, K. Zhou, Z. Luo, S. Chaemchuen and F. Verpoort, Adv. Funct. Mater, 2018, 28, 1705048

30. Z. Liang, C. Zhang, H. Yuan, W. Zhang, H. Zheng and R. Cao, Chem. Commun., 2018, 54, 7519-7522.

31. Y. Wang, M. Zhao, Q. Zhao, Q. Li and H. Pang, Nanoscale, 2018, 10, 15755-15762.

32. Z. Hu, Z. Guo, Z. Zhang, M. Dou and F. Wang, ACS Appl. Mater. Inter, 2018, 10, 12651-12658.

33. W. Zang, A. Sumboja, Y. Ma, H. Zhang, Y. Wu, S. Wu, H. Wu, Z. Liu, C. Guan, J. Wang and S. J. Pennycook, ACS Catal., 2018, 8, 8961-8969.

34. W. Yang, T. P. Fellinger and M. Antonietti, J. Am. Chem. Soc., 2011, 133, 206-209.

35. W. Wei, H. Liang, K. Parvez, X. Zhuang, X. Feng and K. Müllen, Angew. Chem. Int. Ed., 2014, 53, 1570-1574.

36. J. Wu, C. Jin, Z. Yang, J. Tian and R. Yang, Carbon, 2015, 82, 562-571.

37. J. Wu, Z. Yang, Z. Wang, Q. Sun and R. Yang, Electrochem. Commun., 2014, 42, 46-49.

38. S. Xu, Y. Lv, X. Zeng and D. Cao, Chem. Eng. J., 2017, 323, 502-511.

39. R. Wu, X. Qian, F. Yu, H. Liu, K. Zhou, J. Wei and Y. Huang, J. Mater. Chem. A, 2013, 1, 11126-11129.

40. Y. Zhang, Z. Gao, N. Song and X. Li, Electrochim. Acta, 2016, 222, 1257-1266.

41. X. Xu, R. Cao, S. Jeong and J. Cho, Nano Lett., 2012, 12, 4988-4991.

42. W. Xia, R. Zou, L. An, D. Xia and S. Guo, Energy Environ. Sci., 2015, 8, 568-576.

43. M. Jahan, Q. Bao and K. P. Loh, J. Am. Chem. Soc., 2012, 134, 6707-6713.
44. S. Ci, S. Mao, Y. Hou, S. Cui, H. Kim, R. Ren, Z. Wen and J. Chen, J. Mater. Chem. A, 2015, 3, 7986-7993.

45. Q. Zuo, P. Zhao, W. Luo and G. Cheng, Nanoscale, 2016, 8, 14271-14277.

46. W. Zhang, Z. Y. Wu, H. L. Jiang and S. H. Yu, J. Am. Chem. Soc., 2014, 136, 14385-14388.

47. H. Chen, S. You, Y. Ma, C. Zhang, B. Jing, Z. Cai, B. Tang, N. Ren and J. Zou, Chem. Mater., 2018, 30, 6014-6025.

48. Z. Wang, H. Jin, T. Meng, K. Liao, W. Meng, J. Yang, D. He, Y. Xiong and S. Mu, Adv. Funct. Mater., 2018, 28, 1802596

49. Z. Xiang, D. Cao, L. Huang, J. Shui, M. Wang and L. Dai, Adv. Mater., 2014, 26, 3315-3320

50. D. Guo, R. Shibuya, C. Akiba, S. Saji, T. Kondo and J. Nakamura, Science, 2016, 351, 361-365.

51. B. Y. Xia, Y. Yan, N. Li, H. B. Wu, X. W. Lou and X. Wang, Nat. Energy, 2016, 1, 15006-15013.

52. X. Wang, L. Yu, B. Y. Guan, S. Song and X. W. Lou, Adv. Mater, 2018, 30, 1801211.

53. P. Zhang, F. Sun, Z. H. Xiang, Z. G. Shen, J. Yun and D. P. Cao, Energy Environ. Sci., 2014, 7, 442-450.

54. T. Palaniselvam, B. P. Biswal, R. Banerjee and S. Kurungot, Chem. Eur. J., 2013, 19, 9335-9342.

55. H. Zhong, J. Wang, Y. Zhang, W. Xu, W. Xing, D. Xu, Y. Zhang and X. Zhang, Angew. Chem. Int. Ed., 2014, 53, 14235-14239.

56. Y. Z. Chen, C. Wang, Z. Y. Wu, Y. Xiong, Q. Xu, S. H. Yu and H. L. Jiang, Adv. Mater., 2015, 27, 5010-5016.

57. G. Kresse and J. Furthmüller, Phys. Rev. B, 1996, 54, 11169-11186.

58. G. Kresse and J. Furthmüller, Comput. Mater. Sci., 1996, 6, 15-50.

59. L. Yang, D. Cheng, H. Xu, X. Zeng, X. Wan, J. Shui, Z. Xiang and D. Cao, PNAS, 2018, 115, 6626-6631.

60. H. Xu, D. Cheng, D. Cao and X. Zeng, Nature Catal., 2018, 1, 339-348.

61. D. Odkhuu, D. Shin, R. S. Ruoff and N. Park, Sci. Rep. , 2013, 3, 3276-3276.

62. J. Cravillon, S. Munzer, S. J. Lohmeier, A. Feldhoff, K. Huber and M. Wiebcke, Chem. Mater, 2009, 21, 1410-1412.

63. J. S. Li, S. L. Li, Y. J. Tang, M. Han, Z. H. Dai, J. C. Bao and Y. Q. Lan, Chem. Commun., 2015, 51, 2710-2713.

64. L. Fu, Z. Liu, Y. Liu, B. Han, P. Hu, L. Cao and D. Zhu, Adv. Mater, 2005, 17, 217-221.

65. H. Wu, H. Li, X. Zhao, Q. Liu, J. Wang, J. Xiao, S. Xie, R. Si, F. Yang, S Miao, X. Guo, G. Wang and X. Bao, Energy Environ. Sci., 2016, 9, 3736-3745.

66. J. Han, Y. J. Sa, Y. Shim, C. Min, N. Park, S. H. Joo and S. Park, Angew Chem. Int. Ed., 2015, 54, 12622-12626.

67. M. Zeng, Y. Liu, F. Zhao, K. Nie, N. Han, X. Wang, W. Huang, X. Song, J. Zhong and Y. Li, Adv. Funct. Mater., 2016, 26, 4397-4404.

68. D. H. Deng, L. Yu, X. Q. Chen, G. X. Wang, L. Jin, X. L. Pan, J. Deng, G. Q. Sun and X. H. Bao, Angew. Chem. Int. Ed., 2013, 52, 371-375.

69. W. Qi, W. Liu, B. S. Zhang, X. M. Gu, X. L. Guo and D. S. Su, Angew Chem. Int. Ed., 2013, 52, 14224-14228.

70. G. Wu, N. H. Mack, W. Gao, S. G. Ma, R. Q. Zhong, J. T. Han, J. K Baldwin and P. Zelenay, ACS Nano, 2012, 6, 9764-9776.

71. A. Kongkanand, S. Kuwabata, G. Girishkumar and P. Kamat, Langmuir, 2006, 22, 2392-2396

72. J. K. Nørskov, J. Rossmeisl, A. Logadottir, L. Lindqvist, J. R. Kitchin, T. Bligaard and H. Jónsson, J. Phys. Chem. B, 2004, 108, 17886-17892.

73. I. C. Man, H. Y. Su, F. Calle-Vallejo, H. A. Hansen, J. I. Martínez, N. G. Inoglu, J. Kitchin, T. F. Jaramillo, J. K. Nørskov and J. Rossmeisl, ChemCatChem, 2011, 3, 1159-1165.

74. J. Rossmeisl, Z. W. Qu, H. Zhu, G. J. Kroes and J. K. Nørskov, J. Electroanal. Chem., 2007, 607, 83-89.

75. H. Wu, H. Li, X. Zhao, Q. Liu, J. Wang, J. Xiao, S. Xie, R. Si, F. Yang, S Miao, X. Guo, G. Wang and X. Bao, Energy Environm. Sci., 2016, 9, 3736-3745.

76. Q. Liu, Y. Wang, L. Dai and J. Yao, Adv. Mater, 2016, 28, 3000-3006.

77. M. Wang, T. Qian, J. Zhou and C. Yan, ACS Appl. Mater. Inter., 2017, 9, 5213-5221.

78. L. Yang, L. Shi, D. Wang, Y. Lv and D. Cao, Nano Energy, 2018, 50, 691-698.

79. L. Yang, D. Wang, Y. Lv and D. Cao, Carbon, 2019, 144, 8-14

Publisher's Note Engineered Science Publisher remains neutral with regard to jurisdictional claims in published maps and institutional affiliations. 